\title{
Do Sequence Repeats Play an Equivalent Role in the Choline-binding Module of Pneumococcal LytA Amidase?*
}

\author{
Published, JBC Papers in Press, June 9, 2000, DOI 10.1074/jbc.M004379200
}

\begin{abstract}
Julio Vareał, José L. Saiz $\$$, Consuelo López-Zumelł, Begoña Monterroso Francisco J. Medrano§n, José Luis R. Arrondo\|, Ibon Iloro\|, José Laynezł, José L. García§, and Margarita Menéndezł**

From the $\ddagger$ Instituto de Química-Física “Rocasolano,” Consejo Superior de Investigaciones Científicas (CSIC), Serrano 119, 28006 Madrid, Spain, the §Centro de Investigaciones Biológicas, CSIC, Velázquez 144, 28006 Madrid, Spain, and the $\|$ Grupo de Biomembranas (Unidad asociada al CSIC), Departamento de Bioquímica, Universidad del Pais Vasco, Aptdo 644, 48080 Bilbao, Spain
\end{abstract}

LytA amidase breaks down the $N$-acetylmuramoyl-Lalanine bonds in the peptidoglycan backbone of Streptococcus pneumoniae. Its polypeptide chain has two modules: the $\mathrm{NH}_{2}$-terminal module, responsible for the catalytic activity, and the COOH-terminal module, constructed by six tandem repeats of 20 or 21 amino acids (p1-p6) and a short COOH-terminal tail. The polypeptide chain must contain at least four repeats to efficiently anchor the autolysin to the choline residues of the cell wall. Nevertheless, the catalytic efficiency decreases by 90\% upon deletion of the final tail. The structural implications of deleting step by step the two last (p5 and p6) repeats and the final $\mathrm{COOH}$-tail and their effects on choline-amidase interactions have been examined by comparing four truncated mutants with LytA amidase by means of different techniques. Removal of this region has minor effects on secondary structure content but significantly affects the stability of native conformations. The last 11 amino acids and the $p 5$ repeat stabilize the COOH-terminal module; each increases the module transition temperature by about $6^{\circ} \mathrm{C}$. Moreover, the $p 5$ motif also seems to participate, in a choline-dependent way, in the stabilization of the $\mathrm{NH}_{2}$-terminal module. The effects of choline binding on the thermal stability profile of the mutant lacking the $p 5$ repeat might reflect a cooperative pathway providing molecular communication between the choline-binding module and the $\mathrm{NH}_{2}$-terminal region. The three sequence motives favor the choline-amidase interaction, but the tail is an essential factor in the monomer $\leftrightarrow$ dimer self-association equilibrium of LytA and its regulation by choline. The final tail is required for preferential interaction of choline with LytA dimers and for the existence of different sets of choline-binding sites. The $p 6$ repeat scarcely affects the amidase stability but could provide the proper three-dimensional orientation of the final tail.

The Gram-positive bacterium Streptococcus pneumoniae (pneumococcus) is an important cause of invasive disease in human population throughout the world. The increasing prev-

* This work was supported by Dirección General de Investigación Cientifica y Ténica Grants PB96-0850 and PB96-0809. The costs of publication of this article were defrayed in part by the payment of page charges. This article must therefore be hereby marked "advertisement" in accordance with 18 U.S.C. Section 1734 solely to indicate this fact.

If Present address: Div. of Medicinal Chemistry, School of Pharmacy, University of North Carolina, Chapell Hill, NC 27599-7360.

** To whom correspondence should be addressed. Tel.: 34-915619400; Fax: 34-915642431; E-mail: mmenendez@iqfr.csic.es. alence of antibiotic-resistant strains and suboptimal clinical efficacy of the available vaccine (1) hamper control of pneumococcus. Although the capsular polysaccharide is considered the main virulence factor, the major cell wall lytic enzyme, LytA (the major autolysin from $S$. pneumoniae), by itself or because of the products generated by its activity has also been demonstrated to be an important factor in pathogenesis (2). Taking into account that the pneumococcal LytA autolysin was able to induce a protective response in mice, it has been considered as a putative candidate in the preparation of pneumococcal vaccines (3). The LytA amidase is one of the best known bacterial autolysin that catalyzes the cleavage of the $N$-acetylmuramoylL-alanine bond in the peptidoglycan backbone of pneumococcus and requires the presence of choline residues in the cell wall teichoic acids for activity (4). Genetic approaches have demonstrated that LytA amidase has evolved from the fusion of two independent modules: the $\mathrm{NH}_{2}$-terminal module, responsible for the catalytic activity, and the $\mathrm{COOH}$-terminal module, involved in the recognition and attachment to the cell wall $(5,6)$. The latter, constructed by six repeated units $(p 1-p 6)$ of 20 or 21 residues and a short $\mathrm{COOH}$-terminal tail, can be expressed as an isolated protein, C-LytA,${ }^{1}$ and specifically binds the choline residues contained in the teichoic and lipoteichoic acids of the pneumococcal envelope (6). This type of repeat is present, in varying number and position, in the murein hydrolases of pneumococcus and its bacteriophages (7-9). Moreover, they are present in other proteins with different biological functions but isolated from bacteria with choline in their cell wall (7, 10-12), forming the so-called "choline-binding domain" family.

The LytA amidase exists as a monomer $\leftrightarrow$ dimer equilibrium mediated by the $\mathrm{COOH}$-terminal module (13). LytA dimers are strongly stabilized by choline interaction and can be modeled as prolated ellipsoids bearing at both ends the catalytic region (13). CD titration curves have shown the existence of two different sets of choline-binding sites per LytA or C-LytA subunit, and the dimer stabilization appears to be linked to saturation of the higher affinity sites $(13,14)$. Thermal denaturation experiments suggested a fold of the polypeptide chain in several domains, involving either the $\mathrm{NH}_{2}$ - or the $\mathrm{COOH}$-terminal modules of LytA. Each module unfolds into two steps that can be described as independent two-state transitions (13, 14). The elementary transitions of the isolated $\mathrm{COOH}$-terminal region are close but not identical to those assigned to this module in the complete amidase, particularly in the absence of

\footnotetext{
${ }^{1}$ The abbreviations used are: C-LytA, COOH-terminal module of LytA; FTIR, Fourier transform infrared spectroscopy; DSC, differential scanning calorimetry.
} 
choline, and dissociation of C-LytA dimers seems to be coupled to the higher temperature transition of this module (13).

The precise role played by the six repeat units forming the $\mathrm{COOH}$-terminal module of LytA amidase was investigated by producing serial deletions of these repeats. The biochemical characterization of the truncated mutants revealed that LytA amidase must contain at least four units $(p 1-p 4)$ to efficiently recognize the choline residues of pneumococcal cell wall. However, the truncated proteins lacking the last 11 amino acids (P6 amidase) and one repeat unit (P5 amidase) or two repeat units (P4 amidase) are more sensitive to inhibition by free choline than the LytA amidase, whereas the $\mathrm{NH}_{2}$-terminal catalytic module is insensitive to this ligand (15). In addition, deletion of the last 11 amino acids reduces the catalytic activity of the P6 amidase to $10 \%$ of the wild type enzyme. The fusion of the tail to the sequence of the P5 amidase (P5C amidase) does not restore the full activity of LytA (16). These results indicated the fundamental role played by the tail and the two last repeats of the COOH-terminal module on activity regulation as well as the importance of a proper spatial orientation of the tail residues.

For better understanding of the role of this $\mathrm{COOH}$-terminal region on choline recognition by LytA amidase and the related processes, we have studied the choline binding capacity of the truncated P6, P5, P4, and P5C amidases, as well as the effects of the sequence deletions on the amidase native structure and stability.

\section{MATERIALS AND METHODS}

Protein Purification and Chemicals-LytA, C-LytA, and the truncated P4, P5, P5C, and P6 amidases were purified by affinity chromatography on DEAE-cellulose (17) from Escherichia coli DH1 (pGL100) (18), E. coli DH1 (pCE17) (6), E. coli DH1 (pGL124), E. coli DH1 (pGL102), E. coli DH1 (pGL511), and E. coli C600 (pED3), respectively $(15,16)$. Fractions showing the maximum amidase activity were pooled and analyzed by SDS-polyacrylamide gel electrophoresis (19). The P4 amidase does not contain extra amino acids in the COOH-terminal end, whereas P5, P6, and P5C contain two or three additional amino acids that are not present in the wild type LytA amidase $(15,16)$. Before used, protein samples were extensively dialyzed, at $4{ }^{\circ} \mathrm{C}$, against the appropriate buffer ( $20 \mathrm{~mm}$ phosphate $\mathrm{pH} 8.0$, with or without choline) and then centrifuged at 13,000 rpm for $5 \mathrm{~min}$. Protein concentration was determined spectrophotometrically, using the following molar absorption coefficients at $280 \mathrm{~nm}: 113,750$ (LytA and P6), 105,500 (P5 and P5C), 90,280 (P4) and 62,540 (C-LytA) $\mathrm{m}^{-1} \mathrm{~cm}^{-1}$. Choline concentrations were measured by differential refractometry as reported previously (14). All reagents (Sigma) were of analytical grade.

Circular Dichroism Spectra-Circular dichroism spectra were recorded in a JASCO J-720 spectropolarimeter, fitted with a thermostatted cell holder, and interfaced with a thermostatic bath, as reported elsewhere (20). Far UV spectra were recorded in 0.1-cm-pathlength quartz cells, at a protein concentration of $\sim 0.2 \mathrm{mg} \mathrm{ml}^{-1}$. Near UV CD spectra were registered at $0.5-0.8 \mathrm{mg} \mathrm{ml}^{-1}$ protein concentration in 1 -cm-pathlength quartz cells. The observed ellipticities were converted to mean residue ellipticities $[\Theta]$ using mean molecular masses per residue of 115 (LytA, P6, P5C, and P4 amidases) or 116 (P5 amidase and C-LytA). Thermal denaturation experiments were carried out by increasing the temperature from 13 to $90{ }^{\circ} \mathrm{C}$ at $20^{\circ} \mathrm{C} / \mathrm{h}$ and allowing the temperature to equilibrate for $5 \mathrm{~min}$ before recording the spectra.

The analysis of secondary structure composition was performed by deconvolution of the experimental curves using the Lincomb method (21). The pure component set employed was derived by the convex constrain analysis method $(21,22)$, from a reference data set of 30 proteins, including barnase (23), the fibroblast growth factor (24), the antifungal protein from Aspergillus giganteus, Afp, (25), the porcine seminal protein PSP-I/PSP-II (26), the COOH-terminal module of LytA amidase (C-LytA), and the protein data set from Perczel et al. (27). The first four proteins were introduced to increase the number of $\beta$-structure containing proteins and the chiral contributions in the data base, whereas C-LytA was used as a representative of the choline-dependent autolytic enzymes from $S$. pneumoniae. Deconvolution of the reference spectra by the convex constrain analysis method resulted in the six pure components shown in Fig. 1. Reduction of the component number to five

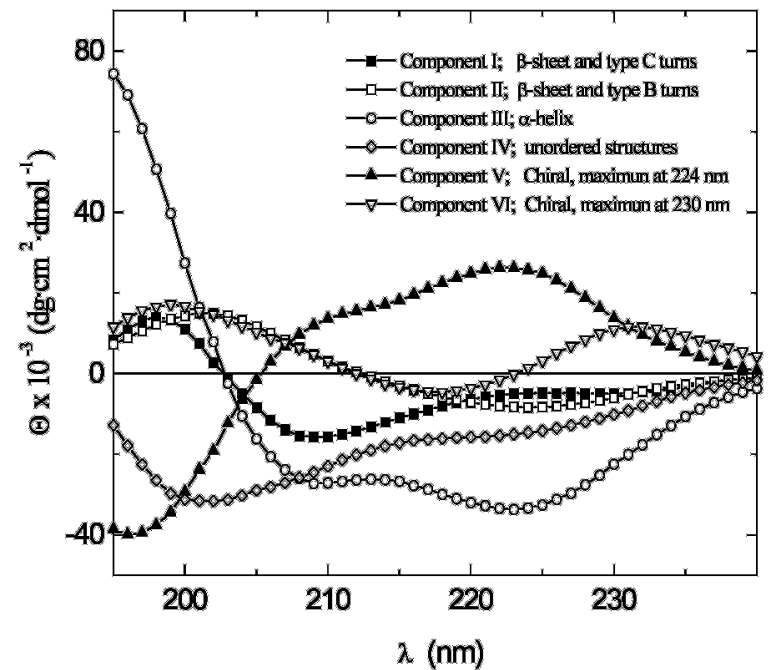

FIG. 1. Theoretical curves corresponding to the six pure components derived by the convex constrain analysis method using the far UV CD spectra of a reference data set of 30 proteins. Component I ( $\square$ ) and II ( $\square$ ) correspond to $\beta$-sheet and turns producing spectra of types $\mathrm{C}$ and $\mathrm{B}$, respectively; component III (O) corresponds to $\alpha$-helix; component IV $(\diamond)$ corresponds to unordered structures; and components $\mathrm{V}(\boldsymbol{\Delta})$ and VI $(\nabla)$ correspond to aromatic chiral contributions.

significantly increased the standard deviation between the experimental and calculated curves (data not shown). The pure components III and IV can be assigned, respectively, to $\alpha$-helical and unordered structures (28-30). Component I can be correlated with $\beta$-sheets and turns producing type C spectra $(28,30,31)$. Similarly, component II can be assigned to antiparallel $\beta$-sheets and/or type B turns $(25,27,28)$. Components V and VI, with maxima at 224 and $230 \mathrm{~nm}$, respectively, can be attributed to the chiral contributions of aromatic side chains $(28,32-34)$.

The temperature-induced changes in protein ellipticity at a given wavelength, normalized over the maximum variation observed, $\Delta \Theta(T) /$ $\Delta \Theta_{\max }$, were theoretically simulated as a linear combination of the variations contributed by the different transitions. For a protein constituted by $m$ independent domains the relative variation in ellipticity at temperature $T$ can be expressed by means of Equation 1 .

$$
\begin{gathered}
\Delta \Theta(T) / \Delta \Theta_{\max }=\sum_{l=1}^{m} \Delta \Theta_{l}(T)=\sum_{l=1}^{m} \sum_{i=1}^{n l} \Delta \Theta_{l, i} \cdot f_{l, i}(T) \\
f_{l, i}(T)=\left(K_{l, 1} \cdot K_{l, 2} \cdots K_{l, i}\right) /\left(1+\sum_{i=1}^{n_{l}} \prod_{j=1}^{i} K_{l, j}\right)
\end{gathered}
$$

where $\Delta \Theta_{l}(T)$ is the contribution of domain $l$ to the ellipticity change at temperature $(T) ; n_{1}$ is the number of steps involved in thermal denaturation of domain $l\left(I_{l, 0} \leftrightarrow I_{l, 1} \leftrightarrow \ldots I_{l, n}\right)$, and $\Delta \Theta_{l, i}$ and $f_{l, i}(T)$ are, respectively, the ellipticity difference between the native form and state $i$ of domain $l$ and the fractional concentration of domain $l$ in state $i$. The $f_{l, i}(T)$ values are given by Equation 2, where $K_{l, j}=\left[I_{l, j}\right] /\left[I_{l, j-1}\right]$ is the constant of equilibrium between states $j$ and $j-1$ of domain $l$. $K_{l, j}$ values at a given temperature $T$, can be evaluated using the thermodynamics parameters derived from DSC experiments by means of Equation 3, where $\Delta H_{l, j}$ and $T_{l, j}$ are the enthalpy change for transition $j$ of domain $l$ and the temperature where $K_{l, j}=1$.

$$
\ln K_{l, j}=\left(-\Delta H_{l, j} / R\right) \cdot\left(T_{l, j}-T\right) /\left(T_{l, j} \cdot T\right)
$$

The use of Equation 1, together with Equations 2 and 3, allows the simulation of the CD denaturation profiles. The $\Delta \Theta_{l, i}$ values for each protein were varied until the best fit to the experimental CD denaturation curves was obtained

Fourier Transform Infrared Spectra-Infrared spectra were recorded at increasing temperatures in a Nicolet Magna 550 FTIR spectrometer, equipped with a MTC detector, by a continuous heating method, using the Series and Rapid Scan software from OMNIC (Nicolet Corp., Madison, WI) following the procedure previously described (35). On average, 
304 interferograms $\mathrm{min}^{-1}$, using a $50-\mu \mathrm{m}$ pathlength, were collected at $2 \mathrm{~cm}^{-1}$ resolution and averaged each minute. Hence, the temperature increment was about $1{ }^{\circ} \mathrm{C} /$ spectrum. After data recording, the interferograms were processed, by rationing in relation to a background, and the spectra were obtained. Protein samples were initially prepared at 0.7 $\mathrm{mg} \mathrm{ml}^{-1}$ in $20 \mathrm{~mm}$ phosphate ( $\mathrm{pH} 8.0$ ), with or without choline. Aliquots containing $300 \mu \mathrm{g}$ of protein were dried and rehydrated by adding $25 \mu \mathrm{l}$ of $\mathrm{D}_{2} \mathrm{O}$ and allowed to undergo proton-deuterium exchange, until the amide band was invariant with time. Data treatment and band decomposition of the original amide I have been described elsewhere (36-40). After integrating each component, the corresponding percentages were obtained assuming that the molar absorptions coefficients for the different protein structures were the same.

Sedimentation Equilibrium-Solution samples of $\sim 1.4-\mathrm{mm}$ column length $(80 \mu \mathrm{l})$ were centrifuged to sedimentation equilibrium at 15,000 rpm and $25^{\circ} \mathrm{C}$ in an Optima XL-A analytical ultracentrifuge (Beckman Instruments, Inc.), using 12-mm double-sector six-channel epon-charcoal centerpieces and following the experimental protocol previously described (13). To obtain the weight average apparent molecular weights, a sedimentation equilibrium model for single species was fitted to individual data sets, using the conservation of signal algorithm (41) from the EQASSOC and XLAEQ programs. The partial specific volumes calculated from amino acid composition were 0.722 (P6 and P5C amidases) and 0.719 (P5 and P4 amidases) $\mathrm{ml} \mathrm{g}^{-1}$ (42). The specific volume of choline measured with a DM2 Paar precision density meter was $0.885 \mathrm{ml}$ $\mathrm{g}^{-1}$. The variations in the calculated specific volumes of the proteins assuming 1-3 mol of bound ligand/amidase monomer were less than $0.3 \%$.

Analytical Size Exclusion Chromatography-A calibrated Superose 12 FPLC column (Amersham Pharmacia Biotech) was used. The molecular weight markers and samples $\left(30 \mu \mathrm{l}\right.$ at $\left.1 \mathrm{mg} \mathrm{ml}^{-1}\right)$ were eluted at room temperature in $20 \mathrm{~mm}$ phosphate buffer, $\mathrm{pH} 8.0$, with or without choline, at $0.5 \mathrm{ml} \mathrm{min}{ }^{-1}$. The solute behavior was characterized as $K_{\text {av }}$ $=\left(V_{\mathrm{e}}-V_{0}\right) /\left(V_{\mathrm{t}}-V_{0}\right)$, where $V_{\mathrm{e}}, V_{0}$, and $V_{\mathrm{t}}$ correspond, respectively, to the elution volume of the solute, the void volume, and the total volume of the bed.

Differential Scanning Calorimetry-DSC measurements were performed using either Microcal MC-2 or MCS instruments (Microcal, Inc. Northampton, MA) at a heating rate of $0.33 \mathrm{~K} \mathrm{~min}^{-1}$, unless otherwise stated and under an extra constant pressure of $2 \mathrm{~atm}$. The standard DA-2 and Microcal Origin software were used for data acquisition and analysis. The excess heat capacity functions were obtained after baseline subtraction of the buffer base line. The reversibility of the thermal transitions was checked by reheating the samples after a first scan. The transitions corresponding to denaturation of the $\mathrm{NH}_{2}$-terminal module were always found to be irreversible, but thermal unfolding of the $\mathrm{COOH}$-terminal module was partially reversible, particularly at high choline concentrations. A similar behavior was found for the full-length and the four truncated amidases. The reversibility of C-LytA thermal denaturation was strongly dependent on choline concentration, becoming $90-100 \%$ reversible under saturating concentrations of ligand. The influence of the irreversible step or steps on the heat capacity curves was checked by running samples at several scanning rates $(0.2,0.75$, and $1 \mathrm{~K} \mathrm{~min}^{-1}$ ). The heat capacity profiles were found to be independent of the scan rate (data not shown); therefore, the kinetic control of the denaturation processes can be discarded, and the thermodynamic analysis of DSC curves is allowed $(43,44)$.

\section{RESULTS}

\section{Protein-Choline Interactions}

The modification of the affinity of LytA for choline derived from truncation of the $\mathrm{COOH}$-terminal module was quantitated by means of choline titration curves monitored by $\mathrm{CD}$ spectroscopy. Simultaneously, the association state of the truncated amidases and its dependence on choline interaction was also investigated.

CD Spectroscopy-Fig. 2 shows the CD spectra of the truncated amidases. In the far UV region, their spectral features are similar to that of LytA amidase. Nevertheless, above 205 $\mathrm{nm}$, deletions of the choline-binding module cause the elliptic$i^{2}{ }^{2}$ values of the mutants to become more negative. In addi-

${ }^{2}$ Changes in the ellipticity values or band intensities towards more negative values are considered as a decrease in the corresponding magnitude. Analogously, shifts towards less negative or positive values are described as increases.

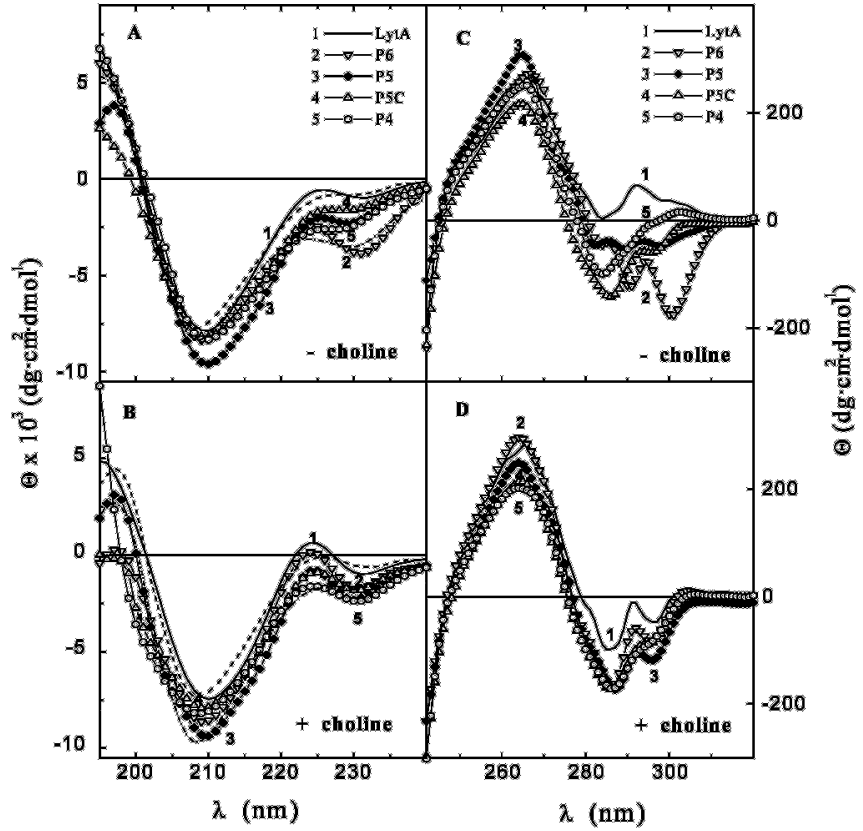

FIG. 2. CD spectra of LytA and the truncated amidases in the far and near UV regions. $A$ and $B$ depict, respectively, the far UV spectra in the absence and in the presence of saturating concentrations of choline (20 mM phosphate buffer, $\mathrm{pH} 8.0)$. Dashed lines are the theoretical curves of LytA, P6, or P4, calculated as indicated under "Materials and Methods." $C$ and $D$ show the near UV spectra in the absence and in the presence of $140 \mathrm{~mm}$ choline in the same buffer conditions as curves in $A$ and $B$.

tion, a slight shift of the minimum centered at $232 \mathrm{~nm}$ toward a lower wavelength is also observed in the spectra of P5, P4, and P5C amidases. In contrast, the deletion of the 11 final amino acids leading to the $\mathrm{P} 6$ amidase significantly enhances this minimum, without shifting it. In P5, P4, and P5C spectra, ligand addition increases the intensities of the maxima centered at $224 \mathrm{~nm}$, whereas the ellipticity values below $205 \mathrm{~nm}$ become more negative, and the shape of the spectrum approaches that of LytA (Fig. $2 B$ ). The binding of choline to the P6 amidase (Fig. $2 B$, curve 2 ) blue shifts the negative band at 232 $\mathrm{nm}$, making its intensity very similar to those of P4, P5, and $\mathrm{P} 5 \mathrm{C}$. In the near UV region, the spectrum of LytA presents two positive bands, centered at 265 and $292 \mathrm{~nm}$, and two small shoulders at 280 and $304 \mathrm{~nm}$ (Fig. 2C, curve 1).

In the truncated amidases, the positive bands above $280 \mathrm{~nm}$ disappear, and new negative minima at around 284, 290 and $297 \mathrm{~nm}$ are observed. The spectroscopic features of the P6 amidase (Fig. 2C, curve 2) differ again from those of the other truncated amidases, being characterized by two well defined minima centered at 290 and $300 \mathrm{~nm}$. However, at choline saturating concentrations, the near CD spectra of the truncated amidases become very similar in shape, with the shoulder at $280 \mathrm{~nm}$ and the minima at 286 and $296 \mathrm{~nm}$ typical of the wild type amidase in the presence of choline (Fig. $2 D$ ). These results suggest that changes in the environment of the aromatic residues involved in the near $\mathrm{CD}$ spectra that are induced by chain truncation would be largely overcome upon choline binding. In addition, data in Fig. $2 D$ indicate that deletion of the final tail causes the major change in the near UV CD spectra of the choline-bound amidases. Moreover, the modification induced in the spectrum shape at $280 \mathrm{~nm}$ and above suggests that removal of the tail could make the environment of the aromatic residues in P6 similar to that induced by choline binding to LytA.

Fig. $3 A$ shows the relative variations of ellipticity $(\Delta \Theta /$ $\left.\Delta \Theta_{\max }\right)$ as a function of the ligand concentration at the wave- 

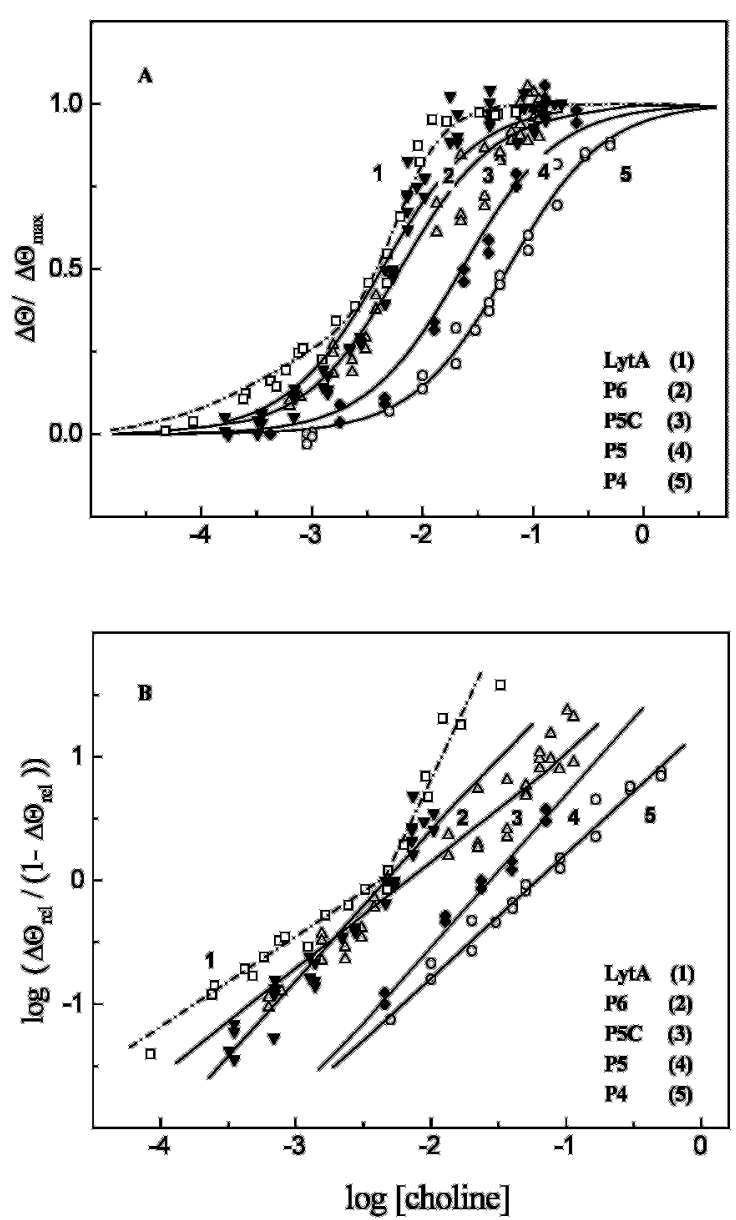

FIG. 3. Choline binding curves of the truncated amidases in 20 mu phosphate buffer (pH 8.0, $\left.25^{\circ} \mathbf{C}\right)$. $\mathbf{\nabla}, \mathrm{P} 6 ; \triangle, \mathrm{P} 5 \mathrm{C} ; \bullet, \mathrm{P} 5 ; \mathrm{O}, \mathrm{P} 4 ; \square$, LytA. Choline concentrations are given in molar units. $A$ depicts the logarithmic plot of the CD choline titration curves calculated using the relative ellipticity changes at the wavelengths of maximum variation in the spectra. Solid lines are the best fitting curves calculated assuming a single set of binding sites for choline binding to the four truncated mutants (see Table I). For comparison, the experimental $(\square)$ and the theoretically calculated (dashed line) choline binding curves of LytA are also represented (14). $B$ presents Hill plots of $\log \left[\Delta \Theta_{\mathrm{rel}} /\left(1-\Delta \Theta_{\mathrm{rel}}\right)\right]$ versus the logarithm of choline concentration of data depicted in $A$ $\Delta \Theta_{\mathrm{rel}}$, is the relative variation in the ellipticity value observed at a given ligand concentration $\left(\Delta \Theta_{\text {rel }}=\Delta \Theta / \Delta \Theta_{\max }\right)$. The lines are the least square linear fit of binding data.

lengths of maximum variation in the spectra. For the sake of comparison, the CD titration curve of LytA is also included (14). Deletion of the final 11 amino acid residues decreases choline binding at low ligand concentrations, but above $5 \mathrm{~mm}$ choline, the P6 and LytA titration curves overlap. The additional deletion of the $p 6$ repeat (P5 amidase) results in a further decrease in affinity, as occurs with removing the $p 5$ repeat (P4 amidase). Furthermore, choline binding becomes less cooperative upon deletion of the $p 6$ repeat, as illustrated by the Hill plot of the binding data shown in Fig. $3 B$. The introduction of the $\mathrm{COOH}$-terminal tail at the end of $\mathrm{P} 5$ slightly improves the affinity for choline (compare P5C to P5) without affecting the cooperativity of the binding. The biphasic character of the LytA titration curve clearly indicates the presence of two sets of choline-binding sites in the full-length amidase $(13,14)$. In contrast, there is no evidence for different sets of binding sites in the truncated proteins, suggesting that the $\mathrm{COOH}$-terminal tail is necessary to differentiate choline-binding sites. For the truncated amidases, the CD titration data can be described in terms of a single type of binding sites. Accordingly, their binding curves yield linear Hill plots, whereas that of LytA is
TABLE I

Apparent affinity constants for choline binding to the P6, P5, P4, and P5C amidases, in $20 \mathrm{~mm}$ phosphate buffer at pH 8.0 and $25^{\circ} \mathrm{C}$, assuming a single set of binding sites

\begin{tabular}{cc}
\hline Protein & $K_{\text {appt }}$ \\
\hline & $M^{-1}$ \\
P6 & $200 \pm 30$ \\
P5 & $42 \pm 6$ \\
P4 & $20 \pm 2$ \\
P5C & $180 \pm 40$ \\
\hline
\end{tabular}

biphasic (Fig. 3B). The P6-choline binding curve slightly deviates, however, from this model, which is likely a consequence of the P6 monomerization induced by choline binding (see below). Table I summarizes the apparent equilibrium constants estimated by fitting the equation derived for a single set of binding sites to choline binding data (45). Curve traces in Fig. $3 A$ are the theoretical curves calculated with this model, using the equilibrium constants from Table I.

Autoassociation of the Truncated Amidases: Choline Dependence-The influence of the COOH-terminal tail and the two final repeats of the choline-binding module in the autoassociation equilibrium of LytA amidase and its regulation by choline have been characterized by analytical ultracentrifugation and size exclusion chromatography. Fig. 4 shows the relative apparent average molecular weight $\left(M_{\mathrm{w}} / M_{0}\right)$ of the truncated amidases (protein concentration $=0.2 \mathrm{mg} \mathrm{ml}^{-1}$ ) as a function of choline concentration in $20 \mathrm{~mm}$ phosphate buffer, $\mathrm{pH}$ 8.0. For comparison, the dependences of LytA (13) and C-LytA selfassociations on choline concentration are also displayed. The arrows on the left ordinate axis indicate the values of the $M_{\mathrm{w}} / M_{0}$ ratios for the unbound proteins. The self-association of the truncated proteins and its dependence on choline concentration is significantly altered in the four mutants. In the absence of ligand, the P6 amidase appears to self-associate to a weight average molecular mass approximately three times that of monomeric P6 (Fig. 4). However, choline binding dissociates the $\mathrm{P} 6$ amidase into monomers, in clear contrast with the dimerization induced in LytA and C-LytA. The additional deletion of one or two repeats eliminates the strong self-association observed in $\mathrm{P} 6$, so that $\mathrm{P} 5$ and $\mathrm{P} 4$ amidases show relative weight average molecular masses somewhat lower than LytA under analogous conditions and their association states become independent of choline binding (Fig. 4). The presence of the $\mathrm{COOH}$-terminal tail at the end of the $p 5$ repeat in $\mathrm{P} 5 \mathrm{C}$ does not affect the autoassociation characteristics of the P5 amidase.

The self-association state of $\mathrm{P} 6$ was further characterized by analytical gel filtration. In the absence of choline (at an initial protein concentration of $1.2 \mathrm{mg} \mathrm{ml}^{-1}$ ), the elution profile shows three peaks characterized by $K_{\mathrm{av}}$ values of $0.02,0.08$, and 0.19 . In the presence of $140 \mathrm{~mm}$ choline, $\mathrm{P} 6$ elutes as a single peak with a $K_{\mathrm{av}}$ of 0.49 . These results are consistent with the presence of multiple association states in the unbound amidase, whereas a single monomeric form is stabilized upon choline binding. The anomalous migration exhibited by the cell wall lytic enzymes from pneumococcus and its bacteriophages (data not shown) precludes the estimation of molecular masses from the corresponding $K_{\text {av }}$ values by means of the column calibration curve. LytA and all the amidases encoded by pneumococcal bacteriophages so far studied eluted with $K_{\text {av }}$ values lower than those expected from their apparent molecular masses. ${ }^{3}$ This might indicate an asymmetrical particle shape (13). In contrast, the monomeric truncated forms of LytA amidase are retarded, suggesting protein-matrix interactions within the column.

${ }^{3}$ J. Varea, J. L. Saiz, C. López-Zumel, B. Monterroso, J. Laynez, J. L. García, and M. Menéndez, unpublished results. 
FIG. 4. Influence of choline binding on the relative apparent average molecular weight, $M_{\mathrm{w}} / M_{0}$, of P6 ( $)$, P5C $(\triangle), P 5(\diamond)$, and P4 $(\bigcirc)$ amidases at a protein concentration of $0.2 \mathrm{mg} \mathrm{ml}^{-1}$ (20 mM phosphate buffer, pH 8.0, $25{ }^{\circ} \mathbf{C}$ ). For comparison, the dependences on choline concentration of $M_{\mathrm{w}} / M_{0}$ for LytA ( $\square$; Ref. 14) and its isolated COOHterminal region, C-LytA $(\oplus)$, are also represented. The arrows on the left ordinate axis indicate the values of the $M_{\mathrm{w}} / M_{0}$ ratios for the unbound proteins. Choline concentration is in molar units.

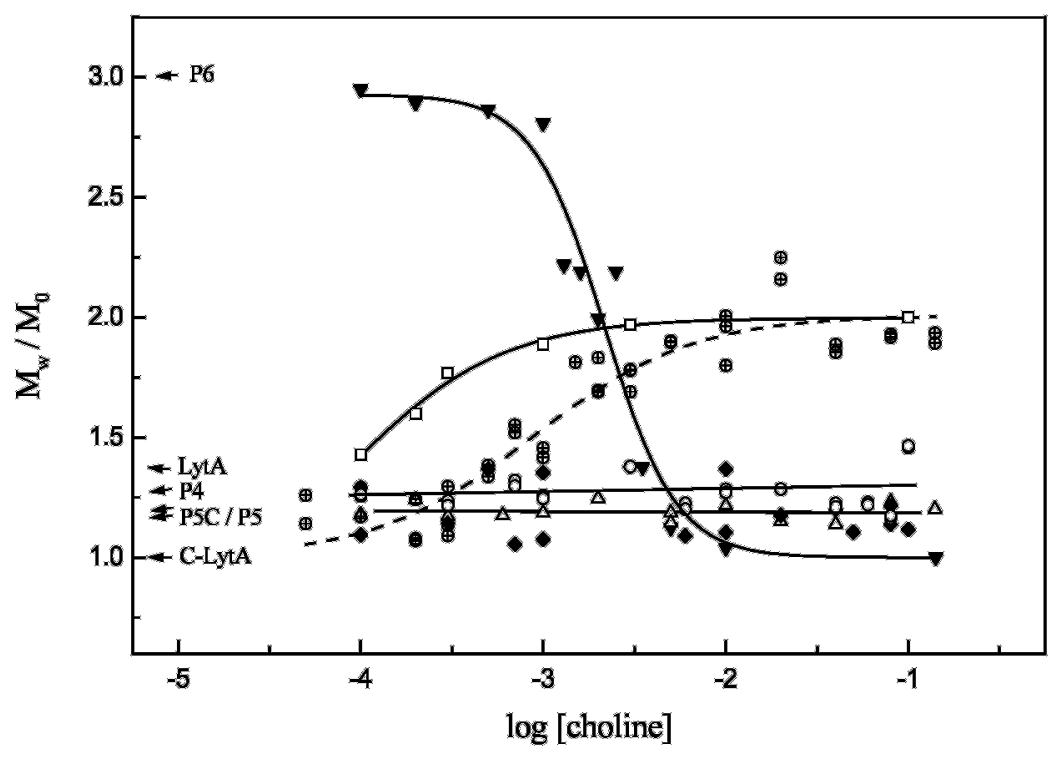

The distinct self-associating behavior of LytA and P6 suggests a fundamental role of the $\mathrm{COOH}$-terminal tail in the amidase dimerization. On the other hand, the differences in the CD spectra of their unbound forms question the equivalence of LytA and P6 self-associated states. Moreover, the spectroscopic features of both amidases become similar in their choline bound forms, when P6 is a monomer and LytA is a dimer.

\section{Characterization of the Native Structure of the Truncated Proteins}

The above results demonstrate the significant role of the COOH-terminal tail and the two last repeats of LytA for choline binding, as well as for the autoassociation equilibrium of the amidase and its regulation by choline. To test whether the observed effects could result from the direct participation of the deleted sequence in these processes or from a conformational change caused by truncation, the native structures of the four mutants were characterized by CD and FTIR spectroscopies and DSC.

Secondary Structure of Truncated LytA Amidases: $C D$ and FTIR Studies-The variations in secondary structure induced by the polypeptide chain modification were formerly evaluated from deconvolution of the far UV CD spectra, as indicated under "Materials and Methods." Dashed lines in Fig. 2 ( $A$ and $B$ ) illustrate the theoretically fitted curves of LytA and P6 or P4 spectra. As could be expected from the similarity of the experimental curves, there are minor differences in the coefficients accounting for secondary structure and chiral contributions to the CD spectra of LytA and the truncated amidases. Concerning chiral contributions, the percentage of component $\mathrm{V}$ (maximum at $224 \mathrm{~nm}$ ) ranges from $25 \%$ in LytA to $14 \%$ in P5 amidase, whereas the contribution of component VI (maximum at $230 \mathrm{~nm}$ ) amounts to $\sim 13 \%$ for all the amidases except P6, whose coefficient is negligible. The percentages contributed by the secondary structure elements to the mutant spectra were, on average: $40 \pm 4 \%$ ( $\beta$-component, type I); $11 \pm 4 \%$ ( $\beta$-component type II); $9 \pm 5 \%$ ( $\alpha$-helix); and $14 \pm 4 \%$ (unordered structures). Similar values were derived for the LytA amidase: $37 \%$ ( $\beta$-component type I); $2 \%$ ( $\beta$-component type II); $25 \%$ ( $\alpha$-helix); and $6 \%$ (random), using the same reference data set. The variations in the component coefficients induced by choline binding are small, except for a moderate increase of about $10 \%$ in the contribution of component VI to the P6 spectrum. However, the presence of high choline concentrations prevent the accurate registration of CD spectra below $200 \mathrm{~nm}$, and deconvolution could lead to an underestimation of the $\alpha$-helix contribution at saturating ligand concentrations.

To get an independent measure of the structural variations introduced by the repeat deletion, the P4 and P5 secondary structures were also studied by FTIR spectroscopy and compared with those of LytA (14). Fig. $5 A$ (solid lines) shows the amide I bands of the P5 amidase in $\mathrm{D}_{2} \mathrm{O}$, both in the absence and in the presence of choline. The band contours show two maxima characteristic of $\alpha$-helix $\left(1653 \mathrm{~cm}^{-1}\right)$ and $\beta$-sheet structures (1637-1634 $\mathrm{cm}^{-1}$ ), whose relative intensities are modified upon choline binding. It is worth noting the high similarity of P5 and LytA spectra (Fig. 5A). The decomposed envelopes of P5 are shown in Fig. $5 B$, and the spectral parameters for the different components are listed in Table II, together with those derived from the analyses of P4 and LytA spectra following the same procedure. The bands at 1634-1637 and $1684-1696 \mathrm{~cm}^{-1}$ correspond to $\beta$-sheet $(37,46,47)$, and those in the $1665-1682 \mathrm{~cm}^{-1}$ frequency range arise from $\beta$-turns $(37,47-49)$. The band at $1653 \mathrm{~cm}^{-1}$ can be assigned to $\alpha$-helix or solvent-shielded peptide bonds (37, 47). Finally, bands at $1624 \mathrm{~cm}^{-1}$ have been found and attributed to either proteinprotein contacts in oligomeric proteins $(38,50)$ or to deuterated $\beta$-strands with intermolecular contacts (51), and they could reflect the monomer-monomer interactions in the amidase dimers. According to their FTIR spectra, the differences among the average content in secondary structure of LytA and P5 are low, although there could be subtle variations in the amount of $\beta$-turns and $\alpha$-helix or loops present.

The analysis of the amide I band under saturating concentrations of choline reveals a slight change in the secondary structure composition that reduces the small differences previously observed in the unligated amidases (Table II), in agreement with CD results. Table III summarizes the secondary structure composition of LytA, P5, and P4 estimated from FTIR and CD spectroscopies. To remove the contributions of the chiral components from the CD data for the purpose of comparing the secondary structure estimates of CD to those of FTIR, the coefficients corresponding to components I-IV (elements of secondary structure) were normalized by rationing each component contribution in relation to the sum of the four component coefficients. The total percentages of $\beta$-structure (turns and sheets) calculated by both techniques are in reasonable agreement. In contrast, the FTIR spectra of native ami- 
FIG. 5. Amide I band of P5 and LytA amidases in $D_{2} O$ buffer. $A$ compares the experimental bands, in arbitrary units, of P5 (solid lines) and the fulllength amidase (dashed lines), with and without choline (thick and thin traces, respectively). $B$ depicts the amide I band decompositions of the truncated enzyme; the parameters corresponding to the component bands are reflected in Table II. The dashed lines are the theoretical envelopes.
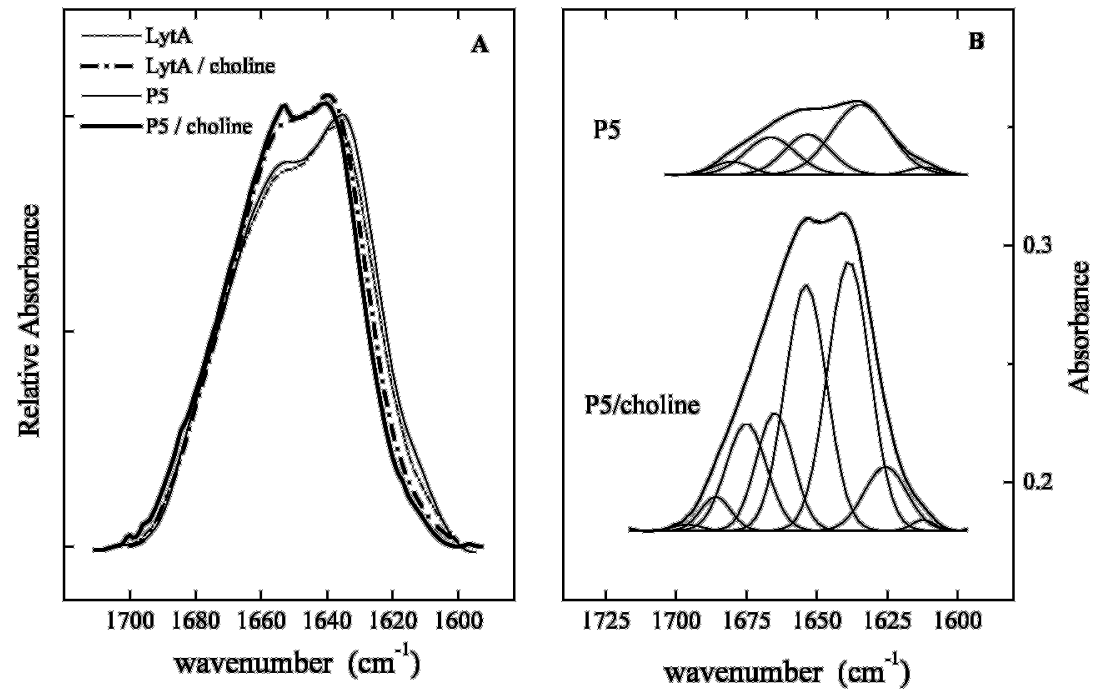

TABLE II

Band frequencies, fractional areas, and proposed structure assignments of the components derived from curve fitting analysis of the amide I band of LytA, P5, and P4 amidases in $\mathrm{D}_{2} \mathrm{O}$ under native conditions

\begin{tabular}{|c|c|c|c|c|c|c|c|c|c|c|}
\hline \multirow{3}{*}{ Assignment } & \multicolumn{4}{|c|}{ LytA } & \multicolumn{4}{|c|}{ P5 } & \multirow{2}{*}{\multicolumn{2}{|c|}{$\begin{array}{c}\mathrm{P} 4 \\
+ \text { Choline }\end{array}$}} \\
\hline & \multicolumn{2}{|c|}{-Choline } & \multicolumn{2}{|c|}{ +Choline } & \multicolumn{2}{|c|}{-Choline } & \multicolumn{2}{|c|}{ +Choline } & & \\
\hline & Band & Area & Band & Area & Band & Area & Band & Area & Band & Area \\
\hline & $\mathrm{cm}^{-1}$ & $\%$ & $\mathrm{~cm}^{-1}$ & $\%$ & $\mathrm{~cm}^{-1}$ & $\%$ & $\mathrm{~cm}^{-1}$ & $\%$ & $\mathrm{~cm}^{-1}$ & $\%$ \\
\hline High frequency $\beta$-sheet & & & 1690 & 1 & & & 1696 & 1 & 1695 & 1 \\
\hline High frequency $\beta$-sheet & & & & & & & 1685 & 4 & 1684 & 4 \\
\hline Turns & 1682 & 6 & 1680 & 7 & 1680 & 6 & 1675 & 11 & & \\
\hline Turns & 1670 & 13 & 1667 & 19 & 1665 & 22 & 1665 & 11 & 1668 & 24 \\
\hline$\alpha$-Helix and no exchangeable loops & 1656 & 32 & 1653 & 31 & 1653 & 20 & 1655 & 30 & 1653 & 33 \\
\hline$\beta$-Sheet & 1635 & 46 & 1637 & 34 & 1634 & 50 & 1638 & 36 & 1637 & 31 \\
\hline Low frequency $\beta$-sheet & 1620 & 1 & 1625 & 4 & & & 1625 & 6 & 1625 & 6 \\
\hline Low frequency $\beta$-sheet & 1611 & 2 & 1616 & 4 & 1611 & 2 & 1613 & 1 & 1612 & 1 \\
\hline
\end{tabular}

TABLE III

Comparison of the secondary structures of LytA, P5, and P4 amidases derived by means of FTIR and far UV CD spectra under native conditions

\begin{tabular}{|c|c|c|c|c|c|c|}
\hline \multirow[b]{2}{*}{ Protein } & \multicolumn{3}{|c|}{ FTIR } & \multicolumn{3}{|c|}{$\mathrm{CD}^{a}$} \\
\hline & Turns & $\beta$-Sheet & $\begin{array}{c}\alpha \text {-Helix and } \\
\text { nonexchangeable } \\
\text { loops }\end{array}$ & $\begin{array}{c}\text { Turns } \\
\text { and } \\
\beta \text {-sheet }\end{array}$ & $\alpha$-Helix & Random \\
\hline & \multicolumn{3}{|c|}{$\%$} & \multicolumn{3}{|c|}{$\%$} \\
\hline LytA & 19 & 49 & 32 & 65 & 25 & 10 \\
\hline P5 & 28 & 52 & 20 & 76 & 5 & 19 \\
\hline LytA/choline & 26 & 43 & 31 & 78 & 16 & 6 \\
\hline P5/choline & 22 & 48 & 30 & 73 & 10 & 17 \\
\hline P4/choline ${ }^{b}$ & 24 & 43 & 33 & 84 & $\mathrm{ND}^{c}$ & 16 \\
\hline
\end{tabular}

${ }^{a}$ The secondary structure composition derived from the analysis of the far UV CD spectra was estimated from the weighted coefficients corresponding to the four secondary structure elements (components I-IV) by rationing each component contribution in relation to the sum of the four coefficients.

${ }^{b}$ P4 FTIR spectra could not be registered in the absence of choline by the low solubility of $\mathrm{P} 4$ under these conditions.

${ }^{c} \mathrm{ND}$, not detected at $140 \mathrm{~mm}$ choline.

dases do not show the band at $1647 \mathrm{~cm}^{-1}$, characteristic of unordered structure, although deconvolution of CD spectra, quite sensitive to it, yielded weighted contributions varying from 6 to $19 \%$ for the random component. Consequently, the contribution of the $1653 \pm 1 \mathrm{~cm}^{-1}$ band yields a higher estimate of $\alpha$-helix content than that obtained from CD spectra for both proteins. This might indicate that the unordered structures present in P5 and P4 could correspond to loops or that the bands at $1653 \mathrm{~cm}^{-1}$ could overlap with those from random forms.
Thermal Stability Profiles of LytA and Its COOH-terminal Truncated Mutants

Differential Scanning Calorimetry-Previous DSC characterization of LytA amidase in phosphate buffer at $\mathrm{pH} 7.0$ showed a complex denaturation mechanism in four steps, two of them involving the $\mathrm{NH}_{2}$-terminal region and the other two from the $\mathrm{COOH}$-terminal part of the molecule (13). The deletions performed in the COOH-terminal module decrease the solubility of the truncated amidases at neutral $\mathrm{pH}$, hampering their characterization under conditions used for the full-length amidase (13). For this reason, the denaturation experiments of the four truncated amidases were performed at $\mathrm{pH}$ 8.0. To quantify the influence of the polypeptide chain length on thermal stability, the DSC denaturation profiles of LytA and its isolated COOH-terminal module, C-LytA, were also obtained at this $\mathrm{pH}$, both in the absence and in the presence of choline (Fig. $6, A$ and $B$ ). At $\mathrm{pH} 8.0$, the thermal denaturation of LytA takes place in three steps centered at around $40.9,49.6$, and $60.0^{\circ} \mathrm{C}$. Choline binding significantly increases the denaturation enthalpy change and the transition temperature of the highest temperature peak without modifying the lower temperature steps but for a moderate decrease in their $T_{\mathrm{i}}$ values as the ligand concentration increases (Fig. 6A). The analysis of the calorimetric profiles shows that denaturation of LytA at $\mathrm{pH} 8.0$ can be resolved into three independent two-state transitions $\left(\Delta H_{\mathrm{i}}=\Delta H_{\mathrm{vHi}}\right)$, whose thermodynamic parameters are summarized in Table IV. The clear influence of choline concentration on the peak at highest temperature allows it to be assigned to the $\mathrm{COOH}$-terminal module, whereas those proceeding at lower 


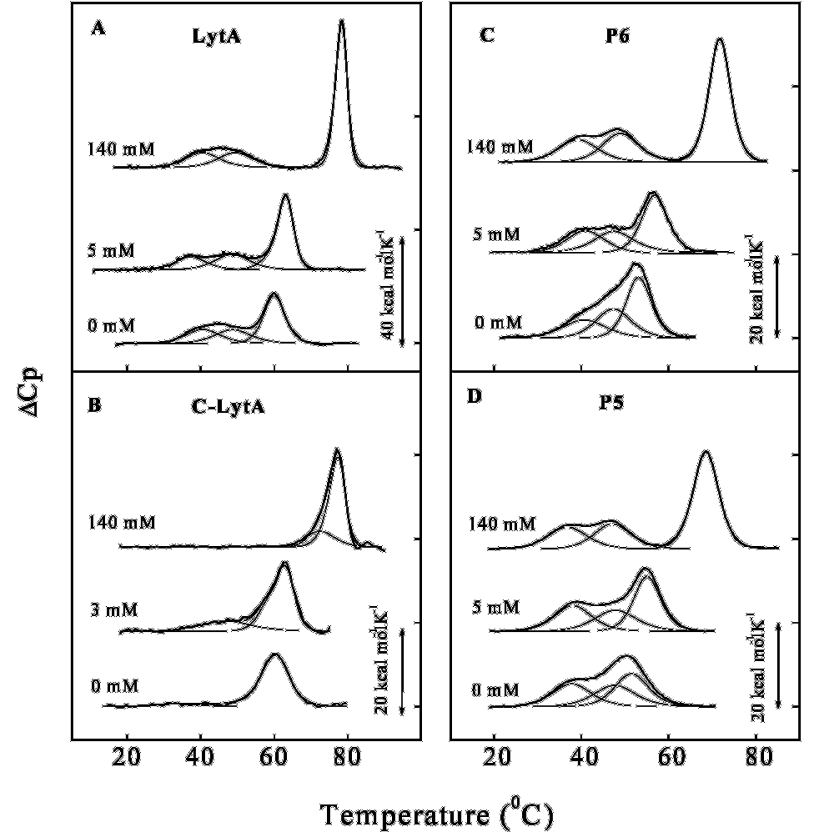

FIG. 6. Influence of the COOH-terminal module length on the DSC transitions of LytA amidase: dependence on choline concentration. $A$ and $B$ represent, respectively, the calorimetric profiles of LytA and its isolated COOH-terminal module, C-LytA, in $20 \mathrm{~mm}$ phosphate buffer, $\mathrm{pH}$ 8.0, at increasing choline concentrations. $C$ and $D$ show the DSC curves corresponding to the P6 and P5 truncated mutants under equivalent buffer conditions. Choline concentrations are indicated in the curve labels. Thin traces depict the results of the deconvolution analysis. (The heat capacity curves for sequential transitions cannot be described in terms of their elementary components.)

temperatures likely correspond to the $\mathrm{NH}_{2}$-terminal region of LytA. The thermodynamic parameters derived for LytA denaturation at $\mathrm{pH} 8.0$ indicate that the $\mathrm{NH}_{2}$-terminal module is slightly destabilized relative to $\mathrm{pH} 7.0$, because its transition temperatures are reduced by about $2^{\circ} \mathrm{C}$, whereas the $\mathrm{COOH}$-terminal region shows an equivalent stabilization by the $\mathrm{pH}$ increase.

The heat capacity curves of the isolated $\mathrm{COOH}$-terminal module, the protein C-LytA, obtained at $\mathrm{pH} 8.0$ and increasing concentrations of choline are shown in Fig. $6 B$. In the absence of the ligand, the heat capacity profile has a main peak, centered at $60.2^{\circ} \mathrm{C}$, and a very small shoulder at lower temperature. The high temperature peak is characterized by a ratio between the calorimetric and the van't Hoff enthalpies of 1.5, indicating the existence of intermediates, whereas the $\Delta H_{\mathrm{i}} /$ $\Delta H_{\mathrm{vHi}}$ value of the shoulder is approximately 0.2. Deconvolution analysis of the experimental profile indicates that the main peak can be explained in terms of two sequential transitions $\left(I_{0} \leftrightarrow I_{1} \leftrightarrow I_{2}\right)$ with $T_{\mathrm{i}}$ values of 57.1 and $60.1^{\circ} \mathrm{C}$ and transition enthalpy changes of 55 and $76 \mathrm{kcal} \mathrm{mol}^{-1}$, respectively (Table V). As the choline concentration increases, the calorimetric enthalpy of the lower temperature transition, $\Delta H_{1}$, increases and approaches the van't Hoff enthalpy change, $\Delta H_{\mathrm{vH} 1}$, becoming equals at around $3 \mathrm{~mm}$ choline, where the high affinity binding sites are saturated (14). At this choline concentration, the analysis of the calorimetric profile shows that C-LytA denaturation can be described in terms of one independent two-state transition, centered at $47.0^{\circ} \mathrm{C}$, plus two sequential two-state transitions with $T_{\mathrm{i}}$ values of 58.8 and $63.5^{\circ} \mathrm{C}$, if the cooperative unit involved into the two last steps is assumed to be a dimer (Fig. $6 B$ and Table V). This is, according to analytical centrifugation, the oligomeric form of C-LytA stabilized at $3 \mathrm{~mm}$ choline and above (Fig. 4). At higher ligand concentrations the region involved in the lower temperature transition is strongly stabilized by saturation of the low affinity choline-binding sites (data not shown), and its denaturation endotherm overlaps at saturating conditions with the highest temperature transition, which is also shifted to higher temperatures. Thus, at $140 \mathrm{~mm}$ choline, the DSC profile of C-LytA presents a single asymmetric peak that can be resolved in two steps characterized by $T_{\mathrm{i}}$ values of 72.5 and $76.7^{\circ} \mathrm{C}$ and $\Delta H / \Delta H_{\mathrm{vH}}$ values of 1 and 0.77 , respectively. The calorimetric enthalpy change for the transition at $76.7^{\circ} \mathrm{C}$ amounts to 125 $\mathrm{kcal} / \mathrm{mol}$ of monomer, which corresponds, approximately, to the sum of the $\Delta H_{\mathrm{i}}$ values derived for the two sequential steps observed at lower choline concentrations. Thus, the reduction of the $\Delta H / \Delta H_{\mathrm{vH}}$ value for this transition could be indicative of variations in the cooperativity of the process. Deconvolution of the calorimetric curve obtained at $140 \mathrm{~mm}$ choline shows that it would be compatible with a model assuming an ABA type of structure for the choline-bound C-LytA dimer, whose denaturation would proceed in two identical two-state transitions corresponding to the A domains $\left(T_{\mathrm{i}}=72.5^{\circ} \mathrm{C}\right)$ and a final step involving denaturation of the $\mathrm{B}$ domain and the dimer dissociation $\left(T_{\mathrm{i}}=76.7^{\circ} \mathrm{C}\right)$.

The variations observed in $\Delta H_{1}$ values at low choline concentrations suggest the presence of two populations of C-LytA molecules with a different degree of cooperativity in their tertiary structure. As the high affinity choline-binding sites become saturated, the equilibrium between both forms seems to be shifted toward the state in which the tertiary structure contacts are preserved, increasing the experimental value of $\Delta H_{1}$, whereas the van't Hoff enthalpy change, $\Delta H_{\mathrm{vH} 1}$, remains constant. In addition, dimer formation seems to trigger intermolecular cooperative interactions, inducing the formation of a cooperative dimeric block, which denatures following a sequential two-step mechanism. The cooperativity of this process is enhanced upon saturation of the low affinity choline-binding sites, and the dimeric block unfolds in a single step under full saturation conditions. Thermal denaturation of C-LytA at $\mathrm{pH}$ 8.0 presents minor differences with the processes observed at neutral $\mathrm{pH}$ (13), although the transitions temperatures are somewhat higher at basic $\mathrm{pH}$.

The $T_{\mathrm{i}}$ value corresponding to thermal denaturation of the $\mathrm{COOH}$-terminal module of LytA is very close to that of the highest temperature transition of C-LytA. Nevertheless, the differences found in the cooperativity of the process, which proceeds as a single step in the full-length polypeptide chain, indicate that the $\mathrm{NH}_{2}$-terminal module plays a role in the organization of the amidase choline-binding module, particularly at low choline concentrations.

The experimental heat capacity profiles of P6, P5, P5C, and $\mathrm{P} 4$ amidases were obtained both in the absence and presence of increasing choline concentrations. Figs. $6(C$ and $D)$ and 7 depict the experimental curves and the results of deconvolution analysis of P6, P5, and P4 endotherms. In the absence of choline, the thermal denaturation of P6, P5, and P5C (data not shown) can be described in terms of three independent twostate transitions, whereas denaturation of the P4 mutant proceeds in two steps (Table VI). The highest temperature peak in P6, P5, and P5C thermograms, corresponding as in LytA amidase to denaturation of the $\mathrm{COOH}$-terminal module, is shifted upwards by choline interaction, and its enthalpy change is increased by about $93 \mathrm{kcal} \mathrm{mol}^{-1}$, on average. In addition, its $\Delta H / \Delta H_{\mathrm{vH}}$ ratio increases up to values of around 1.8 under choline saturating conditions, indicating that intermediates are formed during denaturation of the $\mathrm{COOH}$-teminal regions of these mutants. This is in contrast with the behavior observed in LytA amidase, whose $\mathrm{COOH}$-terminal module denatures following a two-state transition. Deconvolution of the DSC curves shows that denaturation of the choline-bound truncated 
TABLE IV

Thermodynamic parameters for thermal denaturation of LytA amidase in $20 \mathrm{~mm}$ phosphate buffer, $\mathrm{pH} 8.0$

$\Delta H_{\mathrm{i}}$ values are in $\mathrm{kcal} / \mathrm{mol}$ of monomer. The uncertainty in the experimental values is $\pm 0.2{ }^{\circ} \mathrm{C}$ for $T_{1}$ and $15 \%$ for $\Delta H_{\mathrm{i}}$. Identical values for $\Delta H$ and $\Delta H_{\mathrm{vH}}$ indicate that the corresponding transition was analyzed assuming a two-state model.

\begin{tabular}{|c|c|c|c|c|c|c|c|c|c|c|}
\hline Protein & [Choline] & $T_{1}$ & $\Delta H_{1}$ & $\Delta H_{\mathrm{vH} 1}$ & $T_{2}$ & $\Delta H_{2}$ & $\Delta H_{\mathrm{vH} 2}$ & $T_{3}$ & $\Delta H_{3}$ & $\Delta H_{\mathrm{vH} 3}$ \\
\hline & $m M$ & ${ }^{\circ} \mathrm{C}$ & \multicolumn{2}{|c|}{$\mathrm{kcal} \cdot \mathrm{mol}^{-1}$} & ${ }^{\circ} \mathrm{C}$ & \multicolumn{2}{|c|}{$\mathrm{kcal} \cdot \mathrm{mol}^{-1}$} & ${ }^{\circ} \mathrm{C}$ & \multicolumn{2}{|c|}{$\mathrm{kcal} \cdot \mathrm{mol}^{-1}$} \\
\hline \multirow[t]{5}{*}{ LytA } & & 40.9 & 64 & 64 & 49.6 & 62 & 62 & 60.0 & 119 & 119 \\
\hline & 5 & 38.0 & 58 & 58 & 49.5 & 64 & 64 & 63.1 & 140 & 158 \\
\hline & 20 & 37.9 & 52 & 52 & 48.0 & 57 & 57 & 70.2 & 197 & 180 \\
\hline & 40 & 36.6 & 53 & 53 & 48.0 & 57 & 57 & 72.3 & 197 & 190 \\
\hline & 140 & 40.6 & 64 & 64 & 49.4 & 66 & 66 & 78.2 & 224 & 224 \\
\hline$+100 \mathrm{~mm} \mathrm{~L}-\mathrm{Ala}$ & 122 & 44.2 & 18 & 123 & 50.8 & 110 & 93 & 76.7 & 210 & 245 \\
\hline$+100 \mathrm{~mm}$ D-Ala & 122 & 42.8 & 42 & 84 & 50.5 & 69 & 69 & 76.2 & 210 & 231 \\
\hline
\end{tabular}

TABLE V

Thermodynamic parameters for thermal denaturation of C-LytA protein in $20 \mathrm{mM}$ phosphate buffer, $\mathrm{pH} 8.0$

$\Delta H_{\mathrm{i}}$ values are in $\mathrm{kcal} / \mathrm{mol}$ of monomer. The uncertainty in the experimental values is $\pm 0.2{ }^{\circ} \mathrm{C}$ for $T_{\mathrm{i}}$ and $15 \%$ for $\Delta H_{\mathrm{i}}$. Identical values for $\Delta H$ and $\Delta H_{\mathrm{vH}}$ indicate that the corresponding transition was analyzed assuming a two-state model.

\begin{tabular}{|c|c|c|c|c|c|c|c|c|c|}
\hline [Choline] & $T_{1}$ & $\Delta H_{1}$ & $\Delta H_{\mathrm{vH} 1}$ & $T_{2}$ & $\Delta H_{2}$ & $\Delta H_{\mathrm{vH} 2}$ & $T_{3}$ & $\Delta H_{3}$ & $\Delta H_{\mathrm{vH} 3}$ \\
\hline \multirow[t]{2}{*}{$m M$} & ${ }^{\circ} \mathrm{C}$ & \multicolumn{2}{|c|}{$\mathrm{kcal} \cdot \mathrm{mol}^{-1}$} & ${ }^{\circ} \mathrm{C}$ & \multicolumn{2}{|c|}{$\mathrm{kcal} \cdot \mathrm{mol}^{-1}$} & ${ }^{\circ} \mathrm{C}$ & \multicolumn{2}{|c|}{$\mathrm{kcal} \cdot \mathrm{mol}^{-1}$} \\
\hline & 33.9 & 11 & 47 & $57.1^{a}$ & 55 & 55 & $60.1^{a}$ & 76 & 76 \\
\hline 3 & 47.0 & 44 & 44 & $58.8^{a, b}$ & 57 & 114 & $63.5^{a, b}$ & 75 & 150 \\
\hline 10 & 64.1 & 63 & 63 & & & & 66.6 & 107 & 214 \\
\hline 140 & 72.5 & 41 & 41 & & & & 76.7 & $125^{c}$ & 249 \\
\hline
\end{tabular}

${ }^{a}$ Sequential transitions.

${ }^{b} \mathrm{~A}$ two-state model with dimeric cooperative units for the unfolding domain $\left(\Delta H_{\mathrm{i}}=\Delta H_{\mathrm{vHi}} / 2\right)$ was assumed.

${ }^{c}$ A two-state model with dimeric cooperative units for the unfolding domain that dissociate upon denaturation was assumed $\left(X_{2} \leftrightarrow 2 \mathrm{D}\right.$; $\left.\Delta H=\Delta H_{\mathrm{vHi}} / 2\right)$.

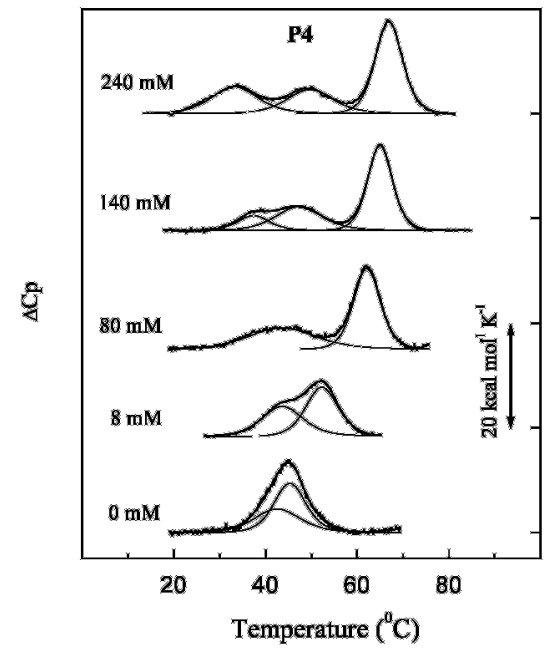

FIG. 7. Thermal stability of the $\mathbf{P 4}$ amidase as a function of choline concentration ( $20 \mathrm{~mm}$ phosphate buffer, $\mathrm{pH}$ 8.0). Ligand concentrations are specified in the curve labels. Thin traces depict the results of the deconvolution analysis.

COOH-terminal regions of $\mathrm{P} 6, \mathrm{P} 5$, and $\mathrm{P} 5 \mathrm{C}$ can be described in terms of two sequential transitions, as the thermal unfolding of the isolated $\mathrm{COOH}$-terminal region, C-LytA. Table VI summarizes the thermodynamic parameters derived for these three mutants at several choline concentrations. The similarity between the two lower temperature transitions of the LytA amidase and those of P6, P5, and P5C, as well as the minor influence of choline binding, allow their assignment to thermal denaturation of the $\mathrm{NH}_{2}$-terminal module.

In contrast with the other mutants, $\mathrm{P} 4$ denaturation displays a complex dependence on the choline concentration. The transition initially centered at $45.4^{\circ} \mathrm{C}$ is shifted to higher temperatures at low ligand concentration, suggesting its relation with the choline-binding module (see below), but the lower temperature transition remains basically unchanged. Further increases in choline concentration results in a higher stabilization of the final transition, which always proceeds as a twostate process. In addition, the lower temperature transition is clearly broadened around half-saturation of the $\mathrm{P} 4$ amidase by choline (Fig. 7). At $140 \mathrm{~mm}$ choline, a new well resolved peak centered at $37.8{ }^{\circ} \mathrm{C}$ is evident in the DSC profile of the $\mathrm{P} 4$ amidase. This peak shifts downward as the ligand concentration is further increased. Table VI summarizes the thermodynamic parameters derived for thermal denaturation of the P4 amidase under various conditions. To check whether the variations induced by choline in the lower temperature transitions of $\mathrm{P} 4$ are due to a nonspecific salt effect associated to the charged nature of choline, the thermal denaturation profile of $\mathrm{P} 4$ was obtained in $140 \mathrm{~mm} \mathrm{NaCl}$. The increase in ionic strength does not affect the denaturation mechanism, which still takes place into two two-state transitions, although the $T_{\mathrm{i}}$ values are somewhat different than those found at low ionic strength (Table VI). The salt presence slightly affects P5C and P5 denaturation (Table VI).

The above results show that the $\mathrm{COOH}$-terminal tail and the p5 repeat make significant contributions to the stability of the choline-binding module. Deletion of the last 11 residues from the $\mathrm{COOH}$ terminus decreases the transition temperature of the COOH-terminal module, $T_{4}$, by more than $7{ }^{\circ} \mathrm{C}$, without significant variations in the $\Delta H_{4}$ value. In contrast, suppression of the $p 6$ repeat and the following 7 residues results in a lower reduction of $T_{4}$. However, the presence of the final tail at the end of the $p 5$ repeat in P5C does not reverse the destabilization observed when the tail was deleted from LytA. Further deletion of the $p 5$ repeat results in an additional reduction of around $6{ }^{\circ} \mathrm{C}$ in $T_{4}$ and a significant decrease of the transition enthalpy change for the remaining $\mathrm{COOH}$-terminal region, particularly in the presence of choline (Table VI). Besides, the marked differences existing between the thermal transitions assigned to the $\mathrm{NH}_{2}$-terminal module in $\mathrm{P} 4$ and the other amidases suggest that the $p 5$ repeat could affect the final organization of the catalytic module. Thermal denaturation of this region in the unbound $\mathrm{P} 4$ amidase takes place in a single step and becomes strongly dependent on choline binding. The variations observed in the DSC profile of P4 as the ligand concentration increases suggest that the thermal denaturation of its $\mathrm{NH}_{2}$-terminal module splits into two steps as the cholinebinding sites become saturated, and its behavior becomes more like those of the other amidases. The former step is progressively destabilized as choline concentration increases, whereas the second transition appears to be shifted upward at high ligand concentrations (Table VI).

To get more evidence about the involvement of the $\mathrm{NH}_{2}$ terminal module in the low temperature transitions, denaturation of LytA, P5, and P4 was measured in the presence of L-Ala, the amino acid moiety involved in the amide bond hy- 
TABLE VI

Choline dependence of the thermal denaturation parameters of the truncated amidases P6, P5C, P5, and P4 in $20 \mathrm{mM}$ phosphate buffer, pH 8.0 The uncertainty in the experimental values is $\pm 0.2{ }^{\circ} \mathrm{C}$ for $T_{\mathrm{i}}$ and $15 \%$ for $\Delta H_{\mathrm{i}}$.

\begin{tabular}{|c|c|c|c|c|c|c|c|c|c|c|c|c|c|c|}
\hline Protein & [Choline] & {$[\mathrm{NaCl}]$} & $T_{1}$ & $\Delta H_{1}$ & $\Delta H_{\mathrm{vH} 1}$ & $T_{2}$ & $\Delta H_{2}$ & $\Delta H_{\mathrm{vH} 2}$ & $T_{3}$ & $\Delta H_{3}$ & $\Delta H_{\mathrm{vH} 3}$ & $T_{4}$ & $\Delta H_{4}$ & $\Delta H_{\mathrm{vH} 4}$ \\
\hline & $m M$ & $m M$ & ${ }^{\circ} \mathrm{C}$ & $k c a$ & $\mathrm{~mol}^{-1}$ & ${ }^{\circ} \mathrm{C}$ & $k c a l$ & $m o l^{-1}$ & ${ }^{\circ} \mathrm{C}$ & $k c a$ & $\mathrm{~mol}^{-1}$ & ${ }^{\circ} \mathrm{C}$ & kcal & $\mathrm{mol}^{-1}$ \\
\hline \multirow{4}{*}{$\mathrm{P} 6$} & & & 40.7 & 58 & 58 & 47.5 & 75 & 75 & & & & 52.9 & 111 & 111 \\
\hline & 5 & & 40.7 & 64 & 64 & 47.4 & 72 & 72 & & & & 56.8 & 119 & 119 \\
\hline & 40 & & 41.7 & 61 & 61 & 48.0 & 73 & 73 & $68.4^{a}$ & 76 & 76 & $63.1^{a}$ & 79 & 79 \\
\hline & 140 & & 39.3 & 64 & 64 & 49.0 & 75 & 75 & $72.0^{a}$ & 88 & 88 & $71.3^{a}$ & 112 & 112 \\
\hline \multirow[t]{5}{*}{ P5C } & & & 38.0 & 56 & 56 & 47.2 & 67 & 67 & & & & 53.6 & 80 & 80 \\
\hline & & 140 & 38.3 & 59 & 59 & 47.4 & 69 & 69 & & & & 53.4 & 81 & 81 \\
\hline & 3 & & 38.5 & 52 & 52 & 48.9 & 59 & 59 & & & & 56.1 & 99 & 99 \\
\hline & 40 & & 38.3 & 61 & 61 & 48.5 & 69 & 69 & $65.0^{a}$ & 72 & 72 & $62.5^{a}$ & 71 & 71 \\
\hline & 140 & & 38.3 & 59 & 59 & 47.4 & 61 & 61 & $68.3^{a}$ & 76 & 76 & $67.4^{a}$ & 88 & 88 \\
\hline \multirow[t]{5}{*}{ P5 } & & & 37.9 & 68 & 68 & 46.4 & 69 & 69 & & & & 50.8 & 92 & 92 \\
\hline & & 140 & 37.8 & 73 & 73 & 45.4 & 89 & 89 & & & & 50.3 & 104 & 104 \\
\hline & 5 & & 40.1 & 61 & 61 & 46.8 & 61 & 61 & & & & 55.1 & 127 & 92 \\
\hline & 40 & & 37.9 & 71 & 71 & 46.0 & 60 & 60 & $60.3^{a}$ & 75 & 75 & $62.6^{a}$ & 107 & 107 \\
\hline & 140 & & 36.8 & 62 & 62 & 47.1 & 69 & 69 & $67.9^{a}$ & 86 & 86 & $68.8^{a}$ & 101 & 101 \\
\hline +100 mM L-Ala & 140 & & $48.1^{a}$ & 78 & 78 & $51.3^{a}$ & 65 & 65 & & & & 68.4 & 138 & 138 \\
\hline \multirow[t]{7}{*}{$\mathrm{P} 4$} & & & & & & 43.6 & 70 & 70 & & & & 45.4 & 71 & 71 \\
\hline & & 140 & & & & 41.5 & 90 & 90 & & & & 46.9 & 88 & 88 \\
\hline & 8 & & & & & 44.5 & 73 & 73 & & & & 52.6 & 96 & 96 \\
\hline & 39 & & & & & 45.7 & 94 & 39 & & & & 59.0 & 97 & 97 \\
\hline & 80 & & & & & 43.2 & 83 & 41 & & & & 62.2 & 112 & 120 \\
\hline & 140 & & 37.8 & 29 & 80 & 47.4 & 60 & 60 & & & & 65.1 & 114 & 114 \\
\hline & 240 & & 33.3 & 60 & 60 & 49.7 & 62 & 62 & & & & 66.9 & 137 & 118 \\
\hline +100 mM L-Ala & 140 & & $48.7^{a}$ & 56 & 56 & $49.2^{a}$ & 72 & 72 & & & & 65.1 & 120 & 120 \\
\hline+100 mM L-Ala & 240 & & $48.7^{a}$ & 65 & 65 & $49.2^{a}$ & 64 & 64 & & & & 67.5 & 104 & 104 \\
\hline
\end{tabular}

${ }^{a}$ Two-state sequential transitions.

FIG. 8. Stabilization of the $\mathrm{NH}_{2}$-terminal regions of LytA and its truncated derivatives P5 and P4 by L-Ala binding at saturating concentration of choline $(20 \mathrm{~mm}$ phosphate buffer, pH 8.0). $A$ depicts the DSC transitions of LytA in the absence and in the presence of either $100 \mathrm{~mm}$ D-Ala (solid trace) or 100 mM L-Ala (dashed trace). $B$ compares the thermal profiles of P5 (dashed lines) and P4 (solid lines) amidases, under analogous conditions to those in $A$.
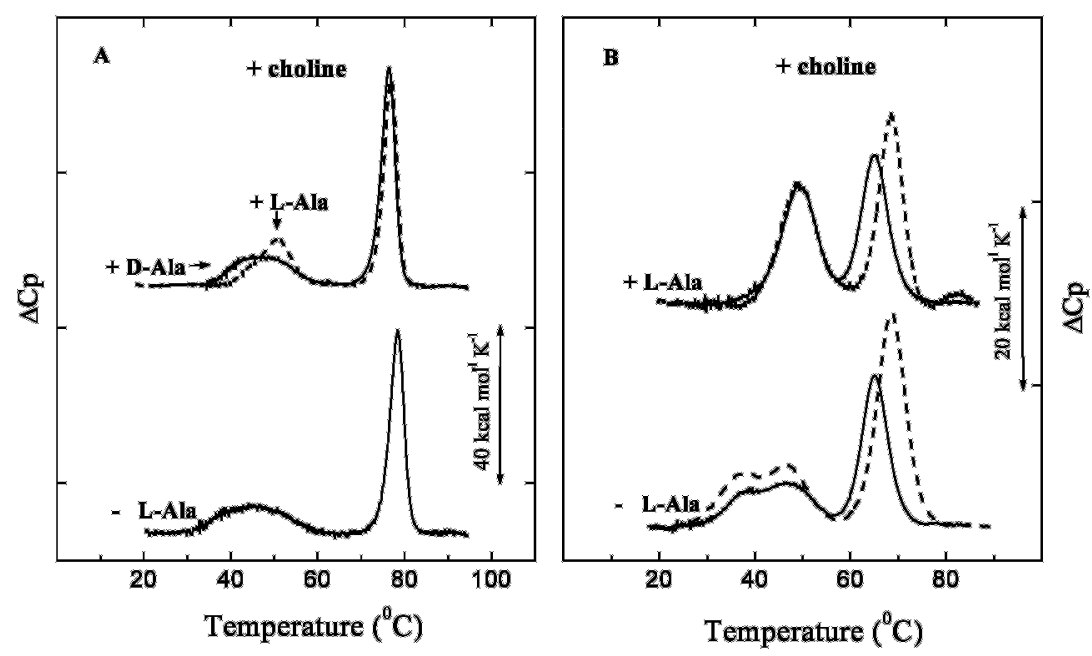

drolyzed by LytA. Fig. $8 A$ displays the calorimetric profiles of LytA in the presence and absence of $100 \mathrm{~mm} \mathrm{~L}$-Ala or D-Ala under saturating concentrations of choline. The distinct effects of each stereoisomer reveal the specificity of L-Ala recognition by its binding loci at the $\mathrm{NH}_{2}$-terminal module. This interaction strongly stabilizes the $\mathrm{NH}_{2}$-terminal region without affecting the transition of the $\mathrm{COOH}$-terminal module. The deconvolution of the excess heat capacity function shows that the lower temperature peak can be resolved into a main transition centered at $50.8^{\circ} \mathrm{C}$ and a very small shoulder at $44.3^{\circ} \mathrm{C}$, characterized, respectively, by $\Delta H / \Delta H_{\mathrm{vH}}$ ratios of 1.2 and 0.2 , approximately. The origin of the very low value of $\Delta H_{1} / \Delta H_{\mathrm{vH} 1}$ is presently unknown. However, the low calorimetric enthalpy change of this transition could indicate that L-Ala binding induces several different conformations of the native $\mathrm{NH}_{2}-$ terminal module, in slow equilibrium, to be populated. On the other hand, the value of 1.2 of the $\Delta H_{2} / \Delta H_{\mathrm{vH} 2}$ ratio could suggest that the second transition slightly deviates from a two-state process, proceeding with intermediate formation (see below).
Fig. $8 B$ depicts the influence of ligand binding on the heat capacity profiles of P4 and P5 amidases. The transition temperatures for the high temperature peaks are identical, within experimental uncertainty, to the values derived for denaturation of their COOH-terminal regions in the absence of L-Ala. However, the low temperature transition is characterized, in both cases, by a $T_{\mathrm{i}}$ value of around $49.3^{\circ} \mathrm{C}$ and a calorimetric enthalpy change of around $125 \mathrm{kcal} \mathrm{mol}^{-1}$. These results reveal the relationship between the low temperature transition that appears in the $\mathrm{P} 4$ thermograms upon choline binding and the transition at around $38^{\circ} \mathrm{C}$ in $\mathrm{P} 5$ thermograms and confirm their assignment to denaturation of the $\mathrm{NH}_{2}$-terminal module. The detailed analysis of the calorimetric profiles shows that, in the presence of $100 \mathrm{~mm} \mathrm{~L}$-Ala, denaturation of the $\mathrm{NH}_{2}$-terminal module of $\mathrm{P} 5$ and $\mathrm{P} 4$ amidases is better accounted for by a model of two sequential transitions (Table VI). This result could reflect the interdependence of the $\mathrm{NH}_{2}$-terminal regions involved in each transition, made evident as the two denaturation steps merge by effect of L-Ala binding (52). Furthermore, the strong influence of L-Ala on $T_{1}$ values could indicate the 
FIG. 9. Comparison of the CD denaturation profiles of LytA (squares), P6 (triangles), and P4 (circles) amidases in $20 \mathrm{~mm}$ phosphate buffer, $\mathrm{pH}$ 8.0. $A$ shows the profiles recorded at 203 $\mathrm{nm}$. Open and solid symbols in this panel correspond to the experimental data in the absence and in the presence of $140 \mathrm{~mm}$ retical curves calculated as described in the text. $B$ and $C$ display, respectively, the ellipticity profiles at $224 \mathrm{~nm}$ versus temperature for the unbound and cholineligated amidases. $\square$, LytA; $\mathbf{\nabla}, \mathrm{P} 6 ; \bigcirc, \mathrm{P} 4$. Choline concentration was $140 \mathrm{~mm}$. The continuous lines correspond to the theoEquation 1 using the parameters shown in Table VII. choline, respectively. Traces are the theoretical curves simulated by means of
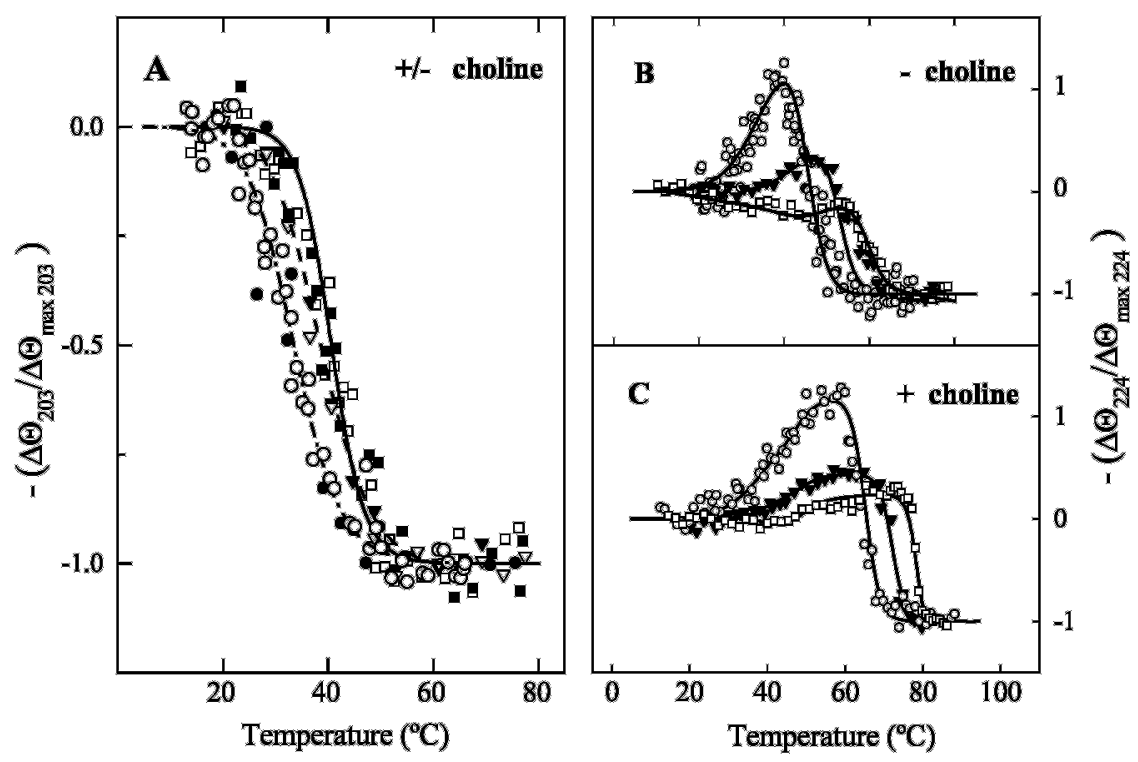

TABLE VII

involvement of $\mathrm{NH}_{2}$-terminal region, accounting for the lower temperature transition into L-Ala recognition. Finally, the similarity among the thermodynamic parameters derived for denaturation of the $\mathrm{NH}_{2}$-terminal region in $\mathrm{P} 4, \mathrm{P} 5$, and LytA amidase upon addition of L-Ala supports the suggestions previously made on the mechanism of denaturation for this module in the full-length amidase.

CD Thermal Denaturation Studies - The analysis of the heat-induced spectroscopic changes in CD spectra can provide additional information on the conformational changes underlying thermal transitions. The variations in the far UV CD spectra upon thermal denaturation of the four mutants have similar patterns. Fig. 9 compares the ellipticity changes at 203 and $224 \mathrm{~nm}$ upon thermal denaturation of LytA with P6 and $\mathrm{P} 4$, the truncated mutants with the largest stability changes. The variation of $\Theta_{203}$ with temperature is monophasic, is independent of choline concentration, and is slightly shifted to lower temperatures as more sequence elements are deleted (Fig. 9A). In contrast, the profiles of $\Theta_{224}$ versus temperature appear to be biphasic in the four mutants, showing an initial increase of ellipticity, followed by a further decrease down to large negative values. Given its dependence on choline concentration, the second step can be correlated with denaturation of the $\mathrm{COOH}$-terminal region; the highest temperature transition in the unligated $\mathrm{P} 4$ thermogram is therefore assigned to this module (Fig. 9, $B$ and $C$ ).

Table VII summarizes the results derived from simulation of the CD transition curves using Equation 1 and the weighted coefficients for the contribution of each step to the total ellipticity change, whereas lineal traces in Fig. 9 are the theoretically simulated curves. Near $203 \mathrm{~nm}$, there seems to be a good correlation between the relative ellipticity change of LytA amidase and the fractional enthalpy change for transition 1 (Fig. 9, solid line), and similar results were found for P5C. However, the fractional changes in $\Delta \Theta_{203}$ upon P6 denaturation are slightly higher at low temperature than those expected from the calorimetric experiments. This difference is significantly larger in P4 amidase, whose CD transition at $203 \mathrm{~nm}$ clearly occurs at lower temperatures than DSC thermal transitions (see Table VII). Simulation of their $\Delta \Theta_{203}$ versus temperature profiles by assuming two-state transitions yield values of $37.8 \pm 0.3\left(\mathrm{P} 6\right.$ amidase) and $33.4 \pm 0.3{ }^{\circ} \mathrm{C}(\mathrm{P} 4$ amidase) for the transition temperatures, which are, respectively, about 1 and $10{ }^{\circ} \mathrm{C}$ lower than their calorimetric $T_{1}$ values in the absence of choline (Table VII). Similar results were found for the P5
Relative contributions of the elementary transitions induced by temperature to the ellipticity changes at 203 and 224 of LytA and the truncated amidases

$\mathrm{N}$ and $\mathrm{C}$ refer to the $\mathrm{NH}_{2}$ - and the $\mathrm{COOH}$-terminal modules.

\begin{tabular}{|c|c|c|c|c|c|c|c|}
\hline \multirow{3}{*}{ Protein } & \multicolumn{3}{|c|}{-Choline } & \multicolumn{4}{|c|}{+ Choline } \\
\hline & \multirow{2}{*}{$T_{\mathrm{i}}$} & \multicolumn{2}{|c|}{$\Delta \Theta_{i} / \Delta \Theta_{\max }$} & \multirow{2}{*}{\multicolumn{2}{|c|}{$T_{\mathrm{i}}$}} & \multicolumn{2}{|c|}{$\Delta_{i} / \Delta \Theta_{\max }$} \\
\hline & & $\lambda_{203}$ & $\lambda_{224}$ & & & $\lambda_{203}$ & $\lambda_{224}$ \\
\hline & ${ }^{\circ} \mathrm{C}$ & & & ${ }^{\circ} \mathrm{C}$ & $C$ & & \\
\hline \multirow{3}{*}{ LytA } & $40.9(\mathrm{~N})$ & 1.0 & 0.1 & 40.6 & $(\mathrm{~N})^{a}$ & 1.0 & 0.1 \\
\hline & $49.6(\mathrm{~N})$ & & -0.3 & 49.4 & $(\mathrm{~N})$ & & -0.3 \\
\hline & $60.0(\mathrm{C})$ & & 0.8 & 71.3 & (C) & & 1.2 \\
\hline \multirow[t]{5}{*}{ P6 } & $37.8^{b}$ & 1.0 & & $37.8^{a,}$ & & 1.0 & \\
\hline & $40.7(\mathrm{~N})$ & & -0.3 & 39.3 & $(\mathrm{~N})$ & & -0.2 \\
\hline & $47.5(\mathrm{~N})$ & & -0.2 & 49.0 & $(\mathrm{~N})$ & & -0.2 \\
\hline & $52.9(\mathrm{C})$ & & 1.5 & 72.0 & $(\mathrm{C})^{c}$ & & 0.3 \\
\hline & & & & 71.3 & $(\mathrm{C})^{c}$ & & 1.1 \\
\hline \multirow[t]{5}{*}{ P5 } & $34.0^{b}$ & 1.0 & & $34.0^{a,}$ & & 1.0 & \\
\hline & $37.9(\mathrm{~N})$ & & -0.5 & 36.8 & $(\mathrm{~N})$ & & -0.4 \\
\hline & $46.4(\mathrm{~N})$ & & & 47.1 & $(\mathrm{~N})$ & & -0.2 \\
\hline & $50.8(\mathrm{C})$ & & 1.5 & 67.9 & $(\mathrm{C})^{c}$ & & 1.0 \\
\hline & & & & 68.8 & $(\mathrm{C})^{c}$ & & 0.6 \\
\hline \multirow{4}{*}{$\mathrm{P} 5 \mathrm{C}$} & $38.0(\mathrm{~N})$ & 0.8 & -0.7 & 38.3 & $(\mathrm{~N})^{a}$ & 0.8 & -0.1 \\
\hline & $47.2(\mathrm{~N})$ & 0.2 & & 47.4 & $(\mathrm{~N})$ & 0.2 & -0.4 \\
\hline & $53.6(\mathrm{C})$ & & 1.7 & 68.3 & $(\mathrm{C})^{c}$ & & 0.7 \\
\hline & & & & 67.4 & $(\mathrm{C})^{c}$ & & 0.8 \\
\hline \multirow[t]{4}{*}{$\mathrm{P} 4$} & $33.5^{b}$ & 1.0 & -1.3 & $33.5^{a,}$ & & 1.0 & -0.4 \\
\hline & $43.3(\mathrm{~N})$ & & -1.5 & 37.8 & $(\mathrm{~N})$ & & -0.2 \\
\hline & $45.4(\mathrm{C})$ & & 3.8 & 47.4 & (N) & & -0.6 \\
\hline & & & & 65.1 & (C) & & 2.2 \\
\hline
\end{tabular}

a $140 \mathrm{~mm}$ choline.

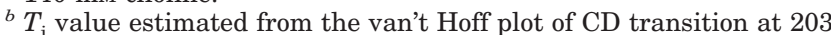
$\mathrm{nm}$, assuming a two-state model.

${ }^{c}$ Sequential transitions.

amidase whose transition at $203 \mathrm{~nm}$ occurs at intermediate temperatures (Table VII).

The simulation of the CD transitions at $224 \mathrm{~nm}$ showed a fairly good agreement with the DSC results for all the amidases except $\mathrm{P} 4$, although some deviations were observed in the absence of choline. $\Delta \Theta_{224}$ of LytA amidase shows a gradual increase with temperature in the pretransition region that account for approximately $19 \%$ of the total variation. This initial slope, which almost completely disappears under saturating concentrations of choline, might reflect the temperature dependence of $\Theta_{224}$ for the native amidase, although the presence of a minor transition not detected by calorimetric techniques cannot be discarded. In addition, the difference existing at high temperature between the fractional change of $\Theta_{224}$ and the 
FIG. 10. Effect of heating on the IR spectra of the $P 5$ amidase in $D_{2} O$. The spectra were acquired in the absence $(A)$ and at saturating concentration of choline $(B)$; the initial temperature was $25^{\circ} \mathrm{C}$, and the temperature interval between two spectra is $2{ }^{\circ} \mathrm{C}$. Fourier self-deconvolution was performed using a resolution enhancement factor of 1.8 .

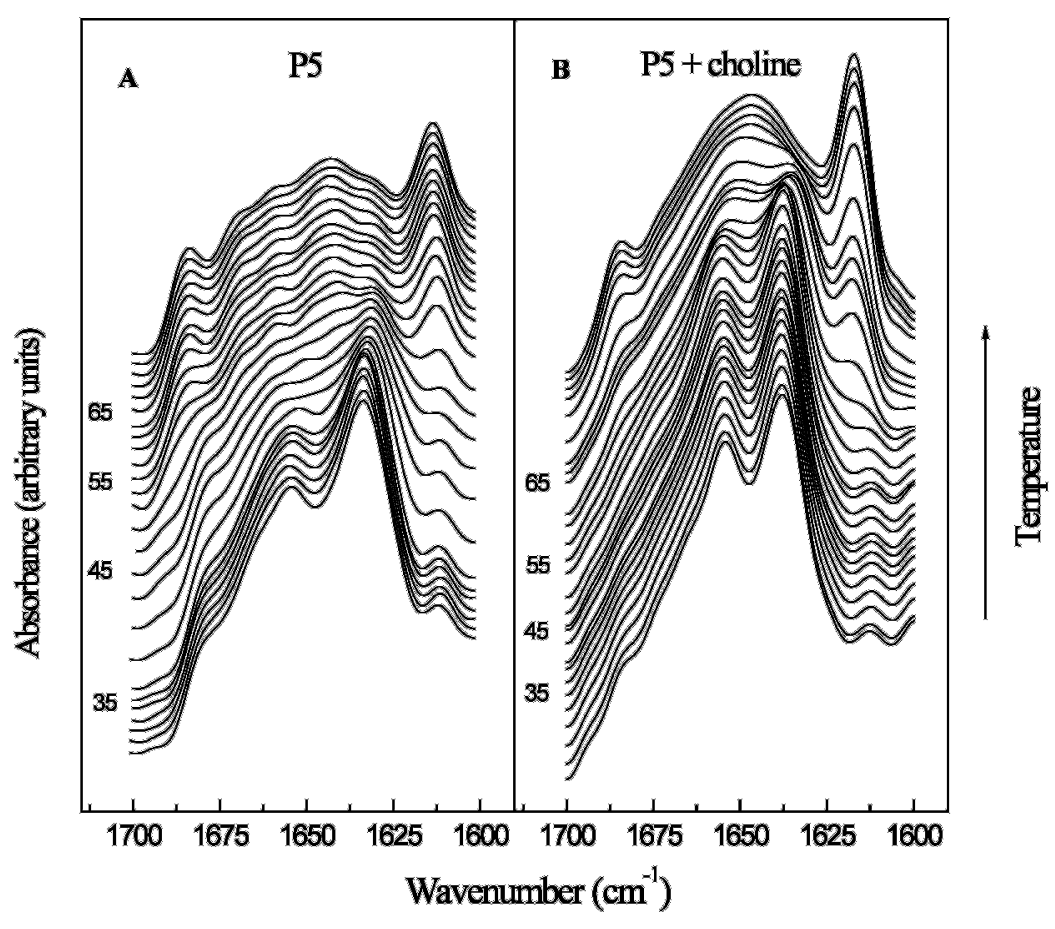

values predicted from DSC for P5 and P6 denaturation in the absence of choline could be related to the disappearance of the 208-nm isosbestic point, generated by amidase denaturation, that takes place at temperatures over $52{ }^{\circ} \mathrm{C}$ (data not shown). No deviations were observed in the choline-bound forms of P6 and P5, whose CD isosbestic points are preserved above the transition temperature range. This could indicate that other events might be competing with P6 and P5 denaturation in the absence of choline, rendering the analysis difficult at high temperature.

In contrast with the behavior observed in the other amidases, the ellipticity changes at $224 \mathrm{~nm}$ induced by temperature increase in the P4 mutant start before the onset of the calorimetric transitions (Fig. 9, $B$ and $C$ ). The low temperature underlying events account for 45 and $33 \%$ of the $\Delta \Theta_{224}$ values measured in the absence and in the presence of choline, respectively, and, according to the $T_{\mathrm{i}}$ values estimated from simulation of the experimental profile (Table VII), they seem to be related to the spectroscopic changes observed at $203 \mathrm{~nm}$.

To ascertain whether the ellipticity changes observed at 203 nm involve a loss of tertiary structure not detected by DSC, the near UV CD spectra of P4 were recorded as a function of temperature, with and without choline. At all the wavelengths tested, the spectroscopic changes present monophasic profiles that are shifted to higher temperatures upon choline binding (data not shown). Their analyses in terms of Equation 1 show a good correlation between the near UV CD transitions and the fraction of heat evolved from denaturation of the $\mathrm{P} 4 \mathrm{COOH}$ terminal domain (Table VII). These results suggest that the near UV region of the spectra only reflects the loss of native tertiary contacts during the thermal denaturation of the choline-binding module and is not sensitive to the structural changes in other amidase regions. Similar results were obtained for the other truncated mutants (data not shown).

The origin of the conformational changes responsible for the increase in $\Theta_{203}$ and for the first step of the ellipticity changes observed at $224 \mathrm{~nm}$ in $\mathrm{P} 4$ amidase remains unknown, as well as the reason why the CD transition found at $203 \mathrm{~nm}$ is not calorimetrically detected. One possible explanation is that the actual calorimetric enthalpy change is lower than the $\Delta H_{\mathrm{vH}}$ value of $42 \pm 4 \mathrm{kcal} \mathrm{mol}^{-1}$ (estimated by means of the van't Hoff equation for the $\mathrm{P} 4$ transition at $203 \mathrm{~nm}$ ) hampering its calorimetric detection. Whatever the case, there seem to be moderate variations in the secondary structure of this mutant below the onset of the calorimetric transitions. According to the deconvolution of the far UV CD spectra recorded at around $30{ }^{\circ} \mathrm{C}$, the contributions of the unordered elements and the chiral component maximizing at $224 \mathrm{~nm}$ could increase by about $8 \%$ with the corresponding reduction in $\beta$-sheet and turns (component I).

The independence of the 203-nm CD transition on choline concentration as well as its total or partial overlap with the calorimetric $\mathrm{NH}_{2}$-terminal transitions in LytA, P5C, and $\mathrm{P} 6$ suggest that this transition would be due to the $\mathrm{NH}_{2}$-terminal module. However, the gap existing between the $T_{\mathrm{i}}$ values derived for the $\Theta_{203}$ transition and the lowest temperature step in the DSC curves of P5 and P4 amidases makes it difficult to ascertain whether, in LytA, P6, and P5C amidases, both processes were almost simultaneous but independent or whether they might be coupled. On the other hand it should be noted that one of the calorimetric step assigned at $\mathrm{pH} 7.0$ to denaturation of the COOH-terminal module (13) is not observed at $\mathrm{pH}$ 8.0. The small difference between the total enthalpy change measured at both $\mathrm{pH}$ levels for denaturation of the $\mathrm{COOH}$ terminal module makes it difficult to determine whether (i) the two processes observed at $\mathrm{pH} 7.0$ take place in a single step at $\mathrm{pH} 8.0$ or (ii) the region involved in the lowest temperature transition might have lost its native tertiary contacts and was further destabilized by the progressive deletions at this $\mathrm{pH}$. The high similarity between thermal unfolding of C-LytA at both $\mathrm{pH}$ levels does not seems to argue in favor of the second possibility, although the existence of differences between the isolated $\mathrm{COOH}$-terminal module and the amidase cannot be discarded.

FTIR Thermal Denaturation Studies -Fig. 10 shows the effect of temperature on the deconvolved amide I band of the P5 amidase in $\mathrm{D}_{2} \mathrm{O}$ buffer. In the absence of choline, the experimental profile remains unchanged up to $35^{\circ} \mathrm{C}$. Above this temperature, the band at $1655 \mathrm{~cm}^{-1}$, characteristic of $\alpha$-helix or nonexchanging loops disappears, and a new band around 
$1660 \mathrm{~cm}^{-1}$ is observed. This change is concomitant with a downward shift of the $\beta$-sheet band from 1632 to $1630 \mathrm{~cm}^{-1}$ and followed by the shift toward higher wave numbers of the band at $1665 \mathrm{~cm}^{-1}$. At higher temperatures $\left(45^{\circ} \mathrm{C}\right)$, a band centered at $1644 \mathrm{~cm}^{-1}$, corresponding to unordered structures, and the doublet band at 1614 and $1684 \mathrm{~cm}^{-1}$, indicative of irreversibly aggregated protein, are clearly observed. In the presence of choline, the spectroscopic features characteristic of the $\mathrm{P} 5$ native structure are well preserved up to $55^{\circ} \mathrm{C}$. Above this temperature the band at $1622 \mathrm{~cm}^{-1}$, assigned to intermolecular interactions disappears. Simultaneously, the doublet band indicative of irreversible aggregation is formed and the $\beta$-sheet band maximum at 1636 moves to $1632 \mathrm{~cm}^{-1}$. In contrast with the results found in the absence of choline, the band at $1644 \mathrm{~cm}^{-1}$ is only observed above $70^{\circ} \mathrm{C}$, and the intensity decrease of the band at $1636 \mathrm{~cm}^{-1}$ is clearly reduced by choline binding. Similar results were found for P4 denaturation at saturating concentrations of choline, although it is shifted to somewhat lower temperatures (data not shown). In addition, the native bands centered at about 1655 and $1635 \mathrm{~cm}^{-1}$ are still visible at $73{ }^{\circ} \mathrm{C}$ in the deconvolved infrared spectra of the $\mathrm{P} 4$ amidase.

It should be emphasized that a small reduction in the secondary structure content is observed during denaturation of both amidases below $35{ }^{\circ} \mathrm{C}$, in agreement with the results derived from the analysis of the CD spectra in the far UV. On the other hand, the appearance of the doublet at 1684 and 1614 $\mathrm{cm}^{-1}$, assigned to protein aggregation, could account for the partial irreversibility of amidase thermal denaturation (see "Materials and Methods"). It might be also related with the significant contribution of component II ( $\beta$-structure) in the high temperature CD spectra of the amidases.

\section{DISCUSSION}

Previous characterization of the enzymatic activities displayed by several mutants of the LytA amidase bearing truncated $\mathrm{COOH}$-terminal modules revealed the dramatic dependence of the catalytic function on the integrity of the cholinebinding region. In this paper we have examined the structural consequences of deleting the two last repeats and the final COOH-terminal tail and how these deletions affect cholineamidase interactions. Four mutants (P6, P5C, P5, and P4 amidases) were used for these studies, and their properties were compared with those of the wild type enzyme, LytA. The reported results clearly demonstrate the relevance of these sequence elements for the structure and function of the amidase.

The serial removal of the final tail and the two last repeats ( $p 6$ and $p 5$ ) scarcely affects the average content in secondary structure of the truncated mutants, although small differences among them and LytA can be inferred from their far UV CD and Fourier transform infrared spectroscopy spectra. These variations could be reflecting either local changes in remaining elements of secondary structure or the intrinsic contributions of the deleted amino acid residues. In contrast, the deleted regions have a larger influence in stabilizing the tertiary native contacts that could extend to both protein modules.

Several conclusions can be drawn from the DSC results: (i) The stability of the $\mathrm{COOH}$-terminal module is particularly sensitive to deletion of the COOH-terminal tail (P6 amidase) and the $p 5$ repeat ( $\mathrm{P} 4$ amidase). Suppression of these regions decrease the transition temperature, $T_{4}$, by more than $6{ }^{\circ} \mathrm{C}$ each, whereas deletion of the $p 6$ repeat only slightly affects the stability of the $\mathrm{COOH}$-terminal region. The cooperativity of the denaturation process for this region is also altered in the choline-bound forms of P6, P5, and P5C and takes place in two steps, in contrast with the single two-state transition exhibited by the $\mathrm{COOH}$-terminal module of the full-length amidase. (ii)
The presence of the final tail at the end of the $p 5$ repeat in $\mathrm{P} 5 \mathrm{C}$ does not reverse the destabilization observed in going from LytA to the P6 amidase. Therefore, it also suggests that the $p 6$ repeat could play a structural role, acting as a physical spacer that allows the native contacts to be formed by the $\mathrm{COOH}$ terminal tail in LytA. (iii) The $p 5$ repeat is important for forming the cooperative interactions that determine the final stability of the $\mathrm{NH}_{2}$-terminal module, because thermal denaturation experiments show that this region behaves as a single cooperative domain in the unligated $\mathrm{P} 4$ amidase. However, the partial recovery of the thermal denaturation features of the $\mathrm{NH}_{2}$-terminal region of LytA upon choline binding reveals that the role of the $p 5$ motif is indirect. Indeed, it should be mediated by a protein conformational change upon $p 5$ deletion, because small differences were detected in the secondary and quaternary structures of the P5 amidase as compared with P4, which lacks the $p 5$ motif.

The differences observed between the thermal denaturations of C-LytA and the COOH-terminal module of LytA amidase as well as the influence of the $p 5$ deletion on thermal stability profiles could be indicative of domain interdependence. If the extent of interdomain interactions were global, then choline binding to the $\mathrm{COOH}$-terminal module would be expected to significantly stabilize the $\mathrm{NH}_{2}$-terminal module, which is in contrast with the experimental data for LytA, P6, P5, and P5C amidases. Nevertheless, the above observations could tentatively be explained assuming that the molecular communication between modules takes place through a cooperative pathway that would involve only specific residues within the $\mathrm{NH}_{2}$ and $\mathrm{COOH}$-terminal modules. The propagation of stability effects through it could extent not only to elements in direct contact but also to distal regions linked by the cooperative interactions, as has been suggested for other systems (53-55). Considering the DSC results, these sequence elements would include residues from the $p 5$ repeat, whose suppression might modify the conformation of other residues of the $\mathrm{COOH}$-terminal region involved in the stabilization of the $\mathrm{NH}_{2}$-terminal module. Similarly, the large changes caused by choline binding on the thermal stability of $\mathrm{P} 4$ cooperative domains also suggests a significant change in the distribution of native conformational states that affect the $\mathrm{NH}_{2}$-terminal module.

Protein-ligand interactions might cause a redistribution of the ensemble of conformational states present in native conditions with a concomitant change in the stability of protein residues affected by ligand binding. The magnitude of these effects will be related to the stability of the residues defining the binding site. Thus, ligand-induced redistribution in the probabilities of the possible conformational states requires that only a subset of the native ensemble conformations were binding-competent. This condition is satisfied when some of the residues that define the binding site have low structural stabilities. On the contrary, if it is formed by high stability residues, all the states in the native ensemble would be bindingcompetent, and ligand binding would only induce an energy shift, without internal reordering of the conformational ensemble. As a consequence, the propagation of stability effects would be limited to the immediate neighborhood of the binding site. The simultaneous presence of regions of high and low stability in ligand-binding sites has been recently found in several proteins (53-55), and it has been suggested that this might be a common structural characteristic of protein-binding sites. Taking into account the significant influence of choline binding in the stabilization of the cooperative domains of the P4 amidase, it could be hypothesized that the residues defining the cholinebinding site might partially exist in a non-binding-competent conformation in the unligated state of $\mathrm{P} 4$ amidase and that 
local perturbations propagate to the $\mathrm{NH}_{2}$-terminal module. If this were the case, the selection by choline of those states that are competent for binding would implicitly include the selection of those conformations in which all the $\mathrm{P} 4$ regions that contribute to the binding site stabilization were also formed. In agreement with the behavior expected for such a model, the $\mathrm{NH}_{2}$ terminal module of $\mathrm{P} 4$ seems to recover, upon choline binding, the characteristic features of domain organization shown by the other amidases. In contrast with this, the results found for the other amidases indicate a limited propagation of structural effects, which is consistent with these proteins having higher stability sites for choline binding. Finally, the induction of similar states by choline binding to the truncated amidases and LytA would agree with the spectroscopic changes induced in $\mathrm{CD}$ and IR spectra upon ligand recognition.

From a macroscopic point of view, the simplest mechanism that would account for the thermal denaturation behavior of $\mathrm{P} 4$ amidase would be that the deletion of $p 5$ would destabilize the partially denatured state associated with the lowest temperature transition of LytA. Thus, the denaturation of the $\mathrm{NH}_{2}$ terminal module of the unligated form of the $\mathrm{P} 4$ amidase would proceed in a single step characterized by a transition temperature intermediate between those corresponding to the two elementary processes observed in the other amidases. Similarly, if the intermediate state becomes stabilized in relation to the native state upon choline binding, denaturation of the $\mathrm{NH}_{2}$-terminal module of $\mathrm{P} 4$ would present two transitions that move apart as choline concentration increases, in agreement with the experimental data. The influence of L-Ala binding on the amidase stability strongly indicates the implication of the $\mathrm{NH}_{2}$-terminal region involved in the lowest temperature transition on L-Ala recognition. On the other hand, the fact that the thermal denaturation of the $\mathrm{NH}_{2}$-terminal module follows a sequential mechanism upon L-Ala binding further reveals the interdependence existing between the $\mathrm{NH}_{2}$-terminal regions involved in the two thermal transitions observed in the absence of this ligand.

According to the spectroscopic and DSC data, the effect of serial deletions on choline binding and on the self-associating behavior of the present mutants should reflect either a direct participation of the deleted element in these events or its implication in the transmission of effects relevant for both processes. The affinity toward choline of the truncated amidases decreases as follows: LytA $\cong \mathrm{C}-\mathrm{LytA}>\mathrm{P} 6>\mathrm{P} 5 \mathrm{C}>\mathrm{P} 5>$ $\mathrm{P} 4$. A Hill plot of binding data strongly indicates that the differences in affinity among the choline-binding sites observed in LytA disappear upon deletion of the final 11 amino acid residues. This modification of the polypeptide chain also affects the self-association behavior of the P6 amidase. This mutant exhibits, in the absence of choline, multiple self-association states. More surprising is the observation that choline binds exclusively to the P6 monomeric form. These results strongly indicate (i) that the deleted sequence participates in the regulation of the amidase self-association processes; (ii) its implication in providing the conformational features that determine the preferential interaction of choline with LytA dimers; and (iii) the appearance of different sets of binding sites. The above implications are further supported by the independence of P5C, $\mathrm{P} 5$, and $\mathrm{P} 4$ self-associating equilibria on choline binding. On the other hand, the failure of choline to stabilize P5C dimers indicates that either the $p 6$ repeat is involved in the cholineinduced dimerization of LytA or that the $\mathrm{COOH}$-terminal tail is badly positioned on deletion of $p 6$. The small stabilization introduced in P5C by the final tail seems to suggest that proper orientation of the final tail is important to achieve the conformational features characteristic of this region in the full-length amidase. Finally, truncation of the polypeptide chain at the ends of the $p 5$ or $p 4$ repeats further decreases the affinity toward choline almost 10 -fold, and it is indicative of their relevance for choline recognition.

It is worth noting the great decrease in catalytic activity derived from deletion of the 11 final amino acid residues, because P6 seems to be quite similar, structurally, to the wild type amidase, except for the differences found in the linkage of self-association to choline binding and for the presence of different sets of choline-binding sites in LytA. Although the affinities of P6 and LytA amidases for free choline are not quite different, the apparent failure of the former to self-associate upon choline binding could greatly increase the differences between them if the local display (concentration and arrangement) of choline residues on the cell wall could allow the simultaneous interaction with multiple sites $(13,14)$. This could further support the functional relevance of self-association equilibria in regulation of amidase activity. Of course, other structural elements could also play a role on the regulation of the amidase-substrate interactions and the complex three-dimensional network that constitute the amidase substrate could also acts as a fine tuner of the amidase activity, sensitive to subtle structural modifications affecting the catalytic efficiency.

This study demonstrates the different effects that the two last repeats and the final $\mathrm{COOH}$-terminal tail have in the structure and function of pneumococcal LytA amidase. Whereas the $p 6$ repeat seems to play a topological role in the structural organization of the $\mathrm{COOH}$-terminal module and enhances the affinity toward choline, the $p 5$ motif is involved in the stabilization of the amidase cooperative domains and also affects the stability of choline-binding sites. Moreover, it seems to participate in a hypothetical cooperative pathway that could allow the molecular communication between the two modules of LytA amidase. Finally, the COOH-terminal tail plays a key role in the self-association equilibria of the amidase and the regulation of these equilibria by choline, having also a significant role in stabilization of the $\mathrm{COOH}$-terminal region. Taken together, these results are indicative of a highly complex and regulated structure, which contrasts with the apparently simple construction of the choline-binding module by means of short sequence repeats.

Acknowledgments-We thank Virginia Obregon for collaboration with protein purification, Victoria López, Eloisa Cano, and Manuel Carrasco for technical assistance, and Douglas V. Laurents for linguistic revision of the manuscript.

\section{REFERENCES}

1. Lipsitch, M., (1999) Emerg. Infect. Dis. 5, 336-345

2. Tuomanen, E., Hengstler, B., Zak, O., and Tomasz, A. (1987) Eur. J. Clin. Microbiol. 5, 682-684

3. Berry, A. M., Lock, R. A., Hansman, D., and Paton, J. C. (1989) Infect. Immun 7, 2324-2330

4. Höltje, J. V., and Tomasz, A. (1975) J. Biol. Chem. 250, 6072-6076

5. Sanz, J. M., Díaz, E., and García, J. L. (1992) Mol. Microbio. 6, 921-931

6. Sánchez-Puelles, J. M., Sanz, J. M., García, J. L., and García E. (1990) Gene (Amst.) 89, 65-75

7. García, J. L., Sánchez-Beato, A. R., Medrano, F. J., and López, R. (1998) Microb. Drug. Res. 4, 25-36

8. García, P., González, M. P., García, E., López, R., and García, J. L. (1999) Mol. Microbiol. 31, 1275-1281

9. García, P., González, M. P., García, E., García, J. L., and López, R. (1999) Mol. Microbiol. 33, 128-138

10. Sánchez-Beato, A. R., and García, J. L., (1996) Gene (Amst.) 180, 13-21

11. Sánchez-Beato, A. R, López, R., and García, J. L. (1998) FEMS Microbiol. Lett. 164, 207-214

12. Brooks-Walter, A., Briles, D. E., and Hollingshead, S. K. (1999) Infect. Immun. 67, 6533-6542

13. Usobiaga P., Medrano, F. J., Gasset, M., García, J. L., Saíz, J. L., Rivas, G., Laynez, J., and Menéndez, M. (1996) J. Biol. Chem. 271, 6832-6838

14. Medrano F. J., Gasset, M., López-Zúmel, C., Usobiaga, P., García, J. L., and Menéndez, M. (1996) J. Biol. Chem. 271, 29152-29161

15. García, J. L., Díaz, E., Romero, A., and García, P. (1994) J. Bacteriol. 176, 4066-4072

16. Sánchez-Puelles, J. M., García, J. L., López, R., and García, E. (1987) Gene (Amst.) 61, 13-19 
17. Sanz, J. M., López, R., and García, J. L. (1988) FEBS Lett. 232, 308-312 18. García, J. L., García, E., and López, R. (1987) Arch. Microbiol. 149, 52-56 19. Laemmli, U. K. (1970) Nature 227, 680-685

20. Menéndez, M., Gasset, M., Laynez, J., López-Zúmel, C., Usobiaga, P., TöfferPetersen, E., and Calvete, J. J. (1995) Eur. J. Biochem. 234, 887-896

21. Perczel, A., Park, K., and Fasman, G. D. (1992) Anal. Biochem. 203, 83-93

22. Perczel, A., Hollóse, M., Tusnady, G., and Fasman, G. D. (1991) Protein Eng. 4, 669-679

23. Hill, C., Dodson, G., Heinemann, V., Saenger, N., Mutsui, Y., Nakamura, K. Borisov, S., Tischenko, G., Polyakov, K., and Pavolovsky, S. (1983) Trends Biochem. Sci. 8, 364-369

24. Romero, A., Pineda. Lucena, A., and Giménez-Gallego, G. (1996) Eur. J. Biochem. 241, 453-461

25. Campos-Olivas, R., Bruix, M., Santoro, J., Lacadena, J., Martínez del Pozo, A. Gavilanes, J., and Rico, M. (1995) Biochemistry 34, 3009-3021

26. Varela, P., Romero, A., Sanz, L., Romao, M. J., Topfer-Petersen, E., and Calvete, J. J. (1997) J. Mol. Biol. 274, 635-649

27. Perczel, A., Park, K., and Fasman, G. D. (1992) Proteins Struct. Funct. Genet 13, 57-69

28. Brahms, S., and Brahms, J. (1980) J. Mol. Biol. 138, 149-178

29. Yang, J. T., Wu, C. C., and Martínez, H. G. (1986) Methods Enzymol. 130 $208-269$

30. Manning, M. C., Illangaseke, M., and Woody, R. W. (1988) Biophys. Chem. 31, $77-86$

31. Woody, R. W. (1974) in Peptides, Polypeptides and Proteins (Blout, E. R. Bovery, F. A., Goodman, M., and Lotan, N., eds) pp 338-350, John Wiley \& Sons, Inc., New York

32. Auer, H. E. (1973) J. Am. Chem. Soc. 95, 3003-3011

33. Day, L. A. (1973) Biochemistry 12, 5329-5339

34. Grishina, I. B., and Woody, R. W. (1994) Faraday Discuss. 99, 245-262

35. Echabe, I., Dornberger, U., Prado, A., Goñi, F. M., and Arrondo, J. L. R. (1998) Protein Sci. 7, 1172-1179

36. Arrondo, J. L. R., Muga, A., Castresana, J., Bernabeu, C., and Goñi, F. M (1989) FEBS Lett. 252, 118-120

37. Arrondo, J. L. R., Muga, A., Castresana, J., and Goñi, F. M. (1993) Prog. Biophys. Mol. Biol. 59, 23-56

38. Arrondo, J. L. R., Castresana, J., Valpuesta, J. M., and Goñi, F. M. (1994)
Biochemistry 33, 11650-11655

39. Bañuelos, S., Arrondo, J. L. R., Goñi, F. M., and Pitaf, G. (1995) J. Biol. Chem. 270, 9192-9196

40. Castresana, J., Muga, A., and Arrondo, J. L. R. (1988) Biochem. Biophys. Res. Commun. 152, 69-75

41. Minton, A. P. (1994) in Modern Analytical Ultracentrifugation (Schuster, T. H. and Lave, T. H., eds) pp. 81-92, Birkhaüser, Boston

42. Laue, T. M., Shah, B. D., Ridgeway, T. M., and Pelletier, S. L. (1992) in Analytical Ultracentrifugation in Biochemistry \& Polymer Science (Harding, S. E., Horton, H. C., and Rowe, A. J. eds) pp. 90-125, Royal Society of Chemistry, London

43. Freire, E., van Osdoll, W. W., Mayorga, O. L., and Sánchez-Ruíz, J. M. (1990) Annu. Rev. Biophys. Chem. 19, 159-188

44. Sánchez-Ruíz, J. M., (1995) in Subcellular Biochemistry: Proteins: Structure, Function and Engineering (Biswas, B. B., and Roy, S., eds) Vol. 24, pp. 133-176, Plenum Press, New York

45. Wyman, J., and Gill, S. (1990) Binding and Linkage, pp. 33-49, University Science Books, Mill Valey, CA

46. Surewicz, W. K., and Mantsch, H. H. (1988) Biophys. Biochim. Acta 952, $115-130$

47. Goormaghtight, E., Cabiaux, V., and Rysschaert, J.-M. (1994) in Subcellular Biochemistry: Physicochemical Methods in the Study of Biomembranes (Helderson, H. J., and Ralston, G. B., eds) Vol. 23, pp. 329-450, Plenum Press, New York

48. Krimm, S., and Bandekar, J. (1986) Adv. Protein Chem. 38, 181-364

49. Susi, H., and Byler, D. M. (1986) Methods Enzymol. 130, 291-311

50. Martínez, A., Haavik, J., Flatmark, T., Arrondo, J. L. R., and Muga, A. (1996) J. Biol. Chem. 271, 19737-19742

51. Susi, H. (1969) in Structure and Stability of Biological Macromolecules (Timasheff, S., N., Stevens, L., eds) pp. 575-663, Dekker, New York

52. Brandts, J. F., Hu, C. Q., Lin, L.-N., and Mas, M. T. (1989) Biochemistry 28 8588-8596

53. Luque, I., Todd, M., Gómez, J., Semo, N., and Freire, E. (1998) Biochemistry 37, 5791-5797

54. Todd, M., Semo, N., and Freire, E. (1993) Biophys. J. 64, 166-170

55. Freire, E. (1999) Proc. Natl. Acad. Sci. U. S. A. 96, 10118-10122 